\title{
Article
}

\section{Salinity Effects on Guard Cell Proteome in Chenopodium quinoa}

\author{
Fatemeh Rasouli ${ }^{1,2,3}$, Ali Kiani-Pouya ${ }^{2,3}$, Lana Shabala ${ }^{1,2}$, Leiting Li ${ }^{3}{ }^{1}$, Ayesha Tahir ${ }^{4}$, Min Yu ${ }^{1}$, \\ Rainer Hedrich ${ }^{5}$, Zhonghua Chen ${ }^{6}$, Richard Wilson ${ }^{7} \mathbb{D}$, Heng Zhang ${ }^{3, * \mathbb{C}}$ and Sergey Shabala ${ }^{1,2, * \mathbb{C}}$
}

1 International Research Centre for Environmental Membrane Biology, Foshan University, Foshan 528000, China; fatemeh.rasouli@utas.edu.au (F.R.); L.Shabala@utas.edu.au (L.S.); yumin0820@hotmail.com (M.Y.)

2 Tasmanian Institute of Agriculture, College of Science and Engineering, University of Tasmania, Hobart, TAS 7001, Australia; ali.kianipouya@utas.edu.au

3 Shanghai Centre for Plant Stress Biology and CAS Centre for Excellence in Molecular Plant Sciences, Chinese Academy of Sciences, Shanghai 201602, China; 1tli@psc.ac.cn

4 Department of Biosciences, COMSATS University Islamabad, Park Road, Islamabad 45550, Pakistan; ayesha.tahir2007@gmail.com

5 Institute for Molecular Plant Physiology and Biophysics, University Wuerzburg, 97082 Wuerzburg, Germany; hedrich@botanik.uni-wuerzburg.de

6 School of Science and Health, Hawkesbury Institute for the Environment, Western Sydney University, Penrith, NSW 2747, Australia; Z.Chen@westernsydney.edu.au

7 Central Science Laboratory, University of Tasmania, Hobart, TAS 7001, Australia; richard.wilson@utas.edu.au

* Correspondence: zhangheng@sibs.ac.cn (H.Z.); sergey.shabala@utas.edu.au (S.S.)

check for

updates

Citation: Rasouli, F.; Kiani-Pouya, A.; Shabala, L.; Li, L.; Tahir, A.; Yu, M.; Hedrich, R.; Chen, Z.; Wilson, R.;

Zhang, H.; et al. Salinity Effects on Guard Cell Proteome in Chenopodium quinoa. Int. J. Mol. Sci. 2021, 22, 428. https://doi.org/10.3390/ijms2201 0428

Received: 2 December 2020 Accepted: 28 December 2020 Published: 4 January 2021

Publisher's Note: MDPI stays neutral with regard to jurisdictional clai$\mathrm{ms}$ in published maps and institutional affiliations.

Copyright: $\odot 2021$ by the authors. Licensee MDPI, Basel, Switzerland. This article is an open access article distributed under the terms and conditions of the Creative Commons Attribution (CC BY) license (https:// creativecommons.org/licenses/by/ $4.0 /)$.

\begin{abstract}
Epidermal fragments enriched in guard cells (GCs) were isolated from the halophyte quinoa (Chenopodium quinoa Wild.) species, and the response at the proteome level was studied after salinity treatment of $300 \mathrm{mM} \mathrm{NaCl}$ for 3 weeks. In total, 2147 proteins were identified, of which $36 \%$ were differentially expressed in response to salinity stress in GCs. Up and downregulated proteins included signaling molecules, enzyme modulators, transcription factors and oxidoreductases. The most abundant proteins induced by salt treatment were desiccation-responsive protein $29 \mathrm{~B}$ ( 50 -fold), osmotin-like protein OSML13 (13-fold), polycystin-1, lipoxygenase, alpha-toxin, and triacylglycerol lipase (PLAT) domain-containing protein 3-like (eight-fold), and dehydrin early responsive to dehydration (ERD14) (eight-fold). Ten proteins related to the gene ontology term "response to ABA" were upregulated in quinoa GC; this included aspartic protease, phospholipase D and plastid-lipidassociated protein. Additionally, seven proteins in the sucrose-starch pathway were upregulated in the GC in response to salinity stress, and accumulation of tryptophan synthase and L-methionine synthase (enzymes involved in the amino acid biosynthesis) was observed. Exogenous application of sucrose and tryptophan, L-methionine resulted in reduction in stomatal aperture and conductance, which could be advantageous for plants under salt stress. Eight aspartic proteinase proteins were highly upregulated in GCs of quinoa, and exogenous application of pepstatin A (an inhibitor of aspartic proteinase) was accompanied by higher oxidative stress and extremely low stomatal aperture and conductance, suggesting a possible role of aspartic proteinase in mitigating oxidative stress induced by saline conditions.
\end{abstract}

Keywords: quinoa; guard cell; stomata; salt stress; proteomics analysis

\section{Introduction}

Photosynthesis, the most important biochemical reaction in the world, will not occur in plants unless carbon dioxide is allowed to enter the leaves through stomatal pores, the apertures of which are controlled by guard cell (GC) movements. At the same time, stomata serve as major getaways for water loss through transpiration. The stomatal pore area may be only as much as $1 \%$ of total leaf surface, but diffusion rates from the leaf could be $95 \%$ as much evaporation as from the stomata [1]. Massive amounts of water and $\mathrm{CO}_{2}$ are passing 
through stomata of plant leaves each year [2], and changes in stomatal aperture in response to environmental factors impact on the flux of both carbon dioxide and water at a global level [3].

Salinity stress is one of the most detrimental environmental stresses that affects water balance through stomatal conductance. Globally, salinity affects 20\% of arable land [4] and represents a major threat to global food security and sustainability of agricultural production systems [5]. Understanding responsive adaptation strategies has a primary role in enhancing the salt tolerance of crop plants and water use efficiency [6]. The plant response to salt stress is a complex trait, regulated by many genes and different pathways [7] that help a plant restore cellular homeostasis, repair the stress damage, and ultimately determine growth rate under salt stress. Salt stress activates signaling pathways related to osmotic, ionic and oxidative stresses, detoxification and growth regulation [8].

As a highly salt tolerant plant species, halophytes have evolved mechanisms to efficiently benefit from adverse saline conditions [9]. In glycophytes, salinity stress reduces stomatal conductance causing a decline in photosynthesis and transpiration rates [6]; this reduction is much smaller in halophytes [10]. Additionally, halophytes have superior abilities to regulate stomata density and size [11].

Studies on stomatal physiology and anatomy have provided insights into understanding stomatal differentiation and function. However, most studies on the effects of environmental stimuli on stomata at the cellular level have used whole leaf samples, which consist of diverse cell types. In such heterogenous samples, it is likely that important mechanisms in response to stimuli related specifically to stomata GCs have been at least partially masked by other more abundant cell types. In recent years, single cell-type analysis has become a popular in the field of biology and plant science. For instance, studies on isolated trichome [12] and epidermal bladder cells [13] and GCs [14,15] have revealed some unique patterns in differential gene expression. However, obtaining purified specialized cells in quantities sufficient for biochemical and standard molecular approaches remains a highly challenging issue that explains the relatively small number of papers published at the single-cell level.

Quinoa (Chenopodium quinoa) is a semi-domesticated halophytic plant with superior abiotic stress tolerance $[16,17]$ including salinity and drought $[11,18]$. Studies investigating the GC response to salt stress in halophytes have to date focused on physiological or anatomical aspects. Given that the stomatal response of halophytes to salt stress is not well understood at the molecular level [10], quinoa represents a highly valuable model plant. However, no studies to date have used global "omics"-based techniques such as proteomics for the discovery of novel adaptive mechanisms in the GCs of halophytes under saline conditions.

A previous study on functional proteomics of Arabidopsis GCs [19] resulted in identification of 1734 unique proteins. Another study compared the proteome of Brassica napus GCs with mesophyll cells [15] leading to the discovery of 74 proteins preferentially expressed in the GCs and 143 proteins with higher abundance in the mesophyll. Specific GC proteins related to thioredoxin signaling [20] or ATP production [14] were also identified. The response of the GC proteome to $\mathrm{CO}_{2}$ levels [21] and abscisic acid (ABA) [22] are to date the only published research papers using proteomics to address the GC response to environmental factors.

Our study applying proteomics to investigate the effects of salt stress on the GCs of sugar beet revealed a significant proportion of differentially expressed proteins related to different abiotic stress e.g., salinity, drought, and oxidative stresses, as well as some proteins related to biotic stress [23]. Salt stress also altered the abundances of some proteins related to signaling, cell wall modification and ATP biosynthesis, indicating the high impact of salt on GCs in sugar beet. Furthermore, high levels of some proteins related to adaptation to oxidative stress under non-saline conditions suggested some constitutively active proteins may play a role in tolerance of GCs to salt stress in the latter species. Here, we sought to 
identify whether similar mechanisms exist in the GCs of halophytic quinoa species, and to what extent they differed from those reported for sugar beet.

It should be commented that most studies using proteomics methods to investigate the response of GCs to environmental factors have employed the model plant Arabidopsis. To the best of our knowledge, this is the first time that an experimental study on proteomics of GCs under salinity stress is reported in halophytes. Investigation of the salt-induced proteins in quinoa GCs as a halophyte species may be instrumental in the identification of salt responsive proteins mediating halophytes adaptation to hyperosmotic saline conditions, at the GC level.

\section{Results}

In the present study, quinoa plants were treated with $300 \mathrm{mM} \mathrm{NaCl}$ for three weeks. In total, searching the acquired tandem mass spectrometry data (MS/MS) against the Chenopodium quinoa (Wild.) protein database identified 2147 proteins, based on two or more matching peptides (Supplemental Table S1).

Rubisco activase (XP_021757275), a lipolytic enzyme GDSL esterase/lipase (XP_021763378), and auxin binding protein ABP19 (XP_021750120) were found to be the three most abundant proteins in quinoa GCs. Rubisco activase is a chloroplastic enzyme that is required for the activation of rubisco; this enzyme is also a responder to various abiotic stresses such as heat, cold, drought and salt stresses and contributes to plant acclimation to a variety of environmental stress [24]. GDSL esterases/lipases are a subfamily of lipolytic enzymes with a wide range of substrates that confer pathogenic resistance to plants [25] - it was the second most abundant protein in quinoa GC.

It is noteworthy that multiple isoforms of peroxidase enzymes, including peroxidase 4 (XP_021732931), peroxidase 12 (XP_021771547) catalase (XP_021754464) and L-ascorbate peroxidase (XP_021745974) and aspartic protease, were also among the top $10 \%$ most abundant proteins in the quinoa GC.

\subsection{Protein Classification in the GC}

In this study, we used protein classification and gene ontology (GO) analysis as complementary tools for bioinformatic analysis of the global quinoa proteomics dataset and the differentially abundant proteins under salinity stress. The Basic Local Alignment Search Tool (BLAST) was first used to obtain the protein sequences of each accession number in GCs' proteome. Amino acid sequences of all GC proteins were used as input in the most recent version of MapMan framework, using Mercator4 software (https:/ / plabipd.de/portal/mercator4) [26] to obtain the functional classification of GC proteins based on homologues of well-annotated proteins such as Arabidopsis.

The Mercator pipeline was used for protein functional classification analysis based on the 2147 quinoa GC proteins identified (Figure 1). This software aligns each set of protein sequence against various databases, including the Conserved Domain Database (CDD), SwissProt/Uniprot plant proteins, TAIR10 proteins, Clusters of Orthologous Groups, and then generates MapMan bin codes. Similar to Kyoto Encyclopedia of Genes and Genomes (KEGG), the MapMan framework uses massive databases spanning many pathways and functional terms but has been specifically developed for plant cell biology. The key functions identified in our dataset included protein synthesis, degradation and folding, signal transduction, post-translational modifications, biotic and abiotic stresses, development, photosynthesis, ion transporter lipid metabolism, and oxido-reductase. The eight most significantly enriched GO categories in the GC proteome are presented in Table 1. Translation, metabolic process, generation of precursor metabolites and energy were also the most significantly enriched GOs, while in most proteomic studies on whole leaf or mesophyll tissue, photosynthesis has been presented among the top GOs. 


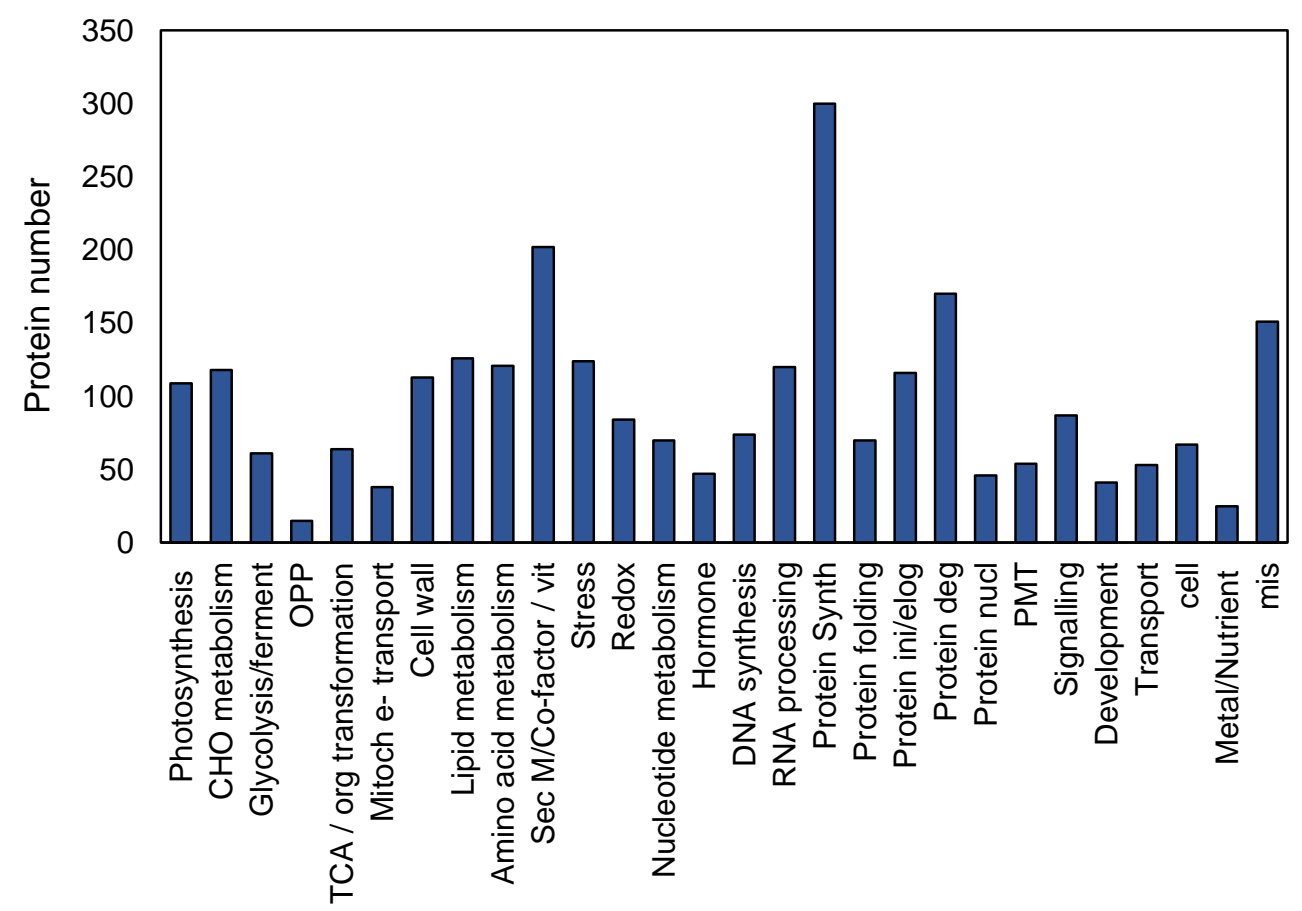

Figure 1. Protein functional classification of quinoa GC proteome based on the identified 2147 proteins. Amino acid sequences of all GC proteins used as input in the most recent version of MapMan framework to obtain the functional classification of GC proteins based on homologues of wellannotated proteins such as Arabidopsis.

Table 1. Top eight gene ontology (GO) terms of quinoa guard cell (GC) proteome.

\begin{tabular}{cccc}
\hline GO Term & Term & Query Item & FDR \\
\hline GO:0006412 & translation & 122 & $2.4 \times 10^{-22}$ \\
GO:0008152 & metabolic process & 854 & $3.1 \times 10^{-18}$ \\
GO:0006091 & generation of precursor metabolites and energy & 46 & $4.5 \times 10^{-15}$ \\
GO:0015979 & photosynthesis & 39 & $3.9 \times 10^{-12}$ \\
GO:0005975 & carbohydrate metabolic process & 115 & $4.4 \times 10^{-12}$ \\
GO:0009056 & catabolic process & 59 & $4.4 \times 10^{-10}$ \\
GO:0009058 & biosynthetic process & 253 & $9.6 \times 10^{-7}$ \\
GO:0006950 & response to stress & 76 & $1.8 \times 10^{-4}$ \\
\hline
\end{tabular}

*False Discovery Rate

\subsection{Signaling Proteins in Quinoa GC Proteome}

The 75 signaling proteins including 14-3-3 proteins, GTP-binding proteins, mitogenactivated protein kinases, calcium-binding protein and proteins involved in light signaling were found in the GC proteome (Table 2). The 14-3-3 proteins are small acidic proteins that form homodimers and heterodimers that bind to phosphorylated target proteins and play a role in stomatal movement through the regulation of blue light responses and plasma membrane and tonoplast channels [27]. G proteins participate in several signal transduction pathways. Mutants lacking the G subunit presented hypo-sensitivity to ABA activation of anion channels and hyposensitivity to ABA inhibition of potassium channels and stomatal opening [22]. 
Table 2. A representative selection of the signaling proteins that were identified in quinoa GC proteome (the complete list of signaling proteins is provided in Supplemental Table S1).

\begin{tabular}{|c|c|c|}
\hline Protein Code & Name & Signal Type \\
\hline XP_021772273 & mitochondrial proton/calcium exchanger protein-like & Calcium \\
\hline XP_021720398 & Calcium-binding EF-hand family protein & Calcium \\
\hline XP_021730224 & probable calcium-binding protein CML13 & Calcium \\
\hline XP_021743759 & calcium-binding allergen Ole e 8-like & Calcium \\
\hline XP_021724195 & calcium-binding protein CML49 & Calcium \\
\hline XP_021740220 & cryptochrome-1-like isoform X3 & Calcium \\
\hline XP_021761282 & calnexin homolog & Calcium \\
\hline XP_021742145 & serine/threonine protein phosphatase $2 \mathrm{~A}$ & Calcium \\
\hline XP_021751211 & 14-3-3-like protein & 14.3 .3 \\
\hline XP_021775698 & 14-3-3-like protein D & 14.3 .3 \\
\hline XP_021772761 & GTP-binding protein SAR1A & G-proteins \\
\hline XP_021772956 & mitochondrial Rho GTPase 1 & G-proteins \\
\hline XP_021760299 & dynamin-related protein $5 \mathrm{~A}$ & G-proteins \\
\hline XP_021768021 & ras-related protein RABD2c-like & G-proteins \\
\hline XP_021763216 & guanylate-binding protein 2-like & G-proteins \\
\hline XP_021738598 & ras-related protein Rab7-like & G-proteins \\
\hline XP_021731959 & nuclear pore complex protein NUP50A-like & G-proteins \\
\hline XP_021765995 & guanylate-binding protein 3-like & G-proteins \\
\hline XP_021736812 & nuclear pore complex protein NUP50A-like & G-proteins \\
\hline XP_021735409 & nucleolin 1-like & G-proteins \\
\hline XP_021748152 & RAN GTPase-activating protein 2 & G-proteins \\
\hline XP_021736812 & nuclear pore complex protein NUP50A & G-proteins \\
\hline XP_021735409 & nucleolin 1-like & G-proteins \\
\hline XP_021748152 & RAN GTPase-activating protein 2 & G-proteins \\
\hline XP_021751681 & G- nucleotide diphosphate dissociation inhibitor & G-proteins \\
\hline XP_021716254 & phototropin-1-like isoform $\mathrm{X} 1$ & Light \\
\hline XP_021740244 & protein EXORDIUM-like & Light \\
\hline XP_021774295 & phytochrome B-like & Light \\
\hline XP_021750479 & NAD(P)-binding Rossmann-fold superfamily & Light \\
\hline XP_021738894 & COP9 signalosome complex subunit 5a-like & Light \\
\hline XP_021714332 & PLC-like phosphodiesterases superfamily & MAP kinases \\
\hline XP_021774801 & mitogen-activated protein kinase MMK1 & MAP kinases \\
\hline XP_021754221 & mitogen-activated protein kinase MMK2 & MAP kinases \\
\hline XP_021723308 & Leucine-rich repeat protein kinase family protein & RK. LRR III \\
\hline XP_021746237 & LRR receptor-like ser/thre-protein kinase & RK. LRR VI \\
\hline XP_021749023 & inactive LLR receptor-like protein kinase & RK. LRR VII \\
\hline XP_021775620 & leucine-rich repeat receptor-like protein kinase & RK. LRR VII \\
\hline XP_021718843 & leucine-rich repeat receptor-like protein kinase & RK. LRR VII \\
\hline XP_021772032 & DNA damage-repair/toleration protein DRT100 & RK. LRR XI \\
\hline
\end{tabular}

\subsection{Transporters Proteins in Quinoa GC Proteome}

Various $A B C$ transporters from $C, F, G$, and I subfamilies were detected in quinoa GCs. $\mathrm{ABC}$ transporters (ATP-binding cassette) contribute to multiple physiological processes that lead to plant adaptation to changing environments, for example, they enhance ABA signaling, which results in a phenotype with reduced transpiration in plants under salt stress conditions [28].

V-ATPases are vacuolar $\mathrm{H}^{+}$pumps that fuel tonoplast $\mathrm{NHX}\left(\mathrm{Na}^{+}, \mathrm{K}^{+} / \mathrm{H}^{+}\right)$exchangers enabling sequestration of toxic $\mathrm{Na}^{+}$into vacuoles, enhancing vacuolar capacity for osmoregulation and maintaining $\mathrm{Na}^{+}$and $\mathrm{K}^{+}$homeostasis [29]. The rate of vacuole-type ATPase activity is constitutively high in GCs compared to other cell-types to meet the requirement of rapid and large ion fluxes across the tonoplast for stomatal movements [30]. In our study, different subunits of V-type ATPase including sub-A, A3, B2, C, D, E and G were identified in quinoa GC (Table 3). 
Table 3. A representative selection of the transporter proteins that were identified in quinoa GC proteome. The full list of transporter proteins is given in Supplemental Table S1.

\begin{tabular}{|c|c|c|}
\hline Accession No. & Name & Transporter \\
\hline XP_021715294 & plasma membrane-associated cation-binding protein & cation \\
\hline XP_021762724 & $\mathrm{ABC}$ transporter $\mathrm{F}$ family member 4-like & $\mathrm{ABC}$ \\
\hline XP_021743351 & $A B C$ transporter $C$ family member 2-like & $\mathrm{ABC}$ \\
\hline XP_021776035 & ABC transporter $\mathrm{G}$ family member 22-like & $\mathrm{ABC}$ \\
\hline XP_021766195 & ABC transporter I family member 19-like & $\mathrm{ABC}$ \\
\hline XP_021720939 & calcium-transporting ATPase 4 & calcium \\
\hline XP_021751211 & calcium-transporting ATPase 10 & calcium \\
\hline XP_021744756 & bifunctional monothiol glutaredoxin-S16 & calcium \\
\hline XP_021760697 & pyrophosphate-energized vacuolar membrane $\mathrm{H}^{+}$pump & $\mathrm{H}^{+}$pump \\
\hline XP_021769151 & probable aquaporin PIP1-4 & PIP \\
\hline XP_021765658 & mitochondrial carnitine/acylcarnitine carrier-like protein & metabolite \\
\hline XP_021738293 & mitochondrial dicarboxylate/tricarboxylate transporter DTC & metabolite \\
\hline XP_021756032 & mitochondrial phosphate carrier protein 3 , mitochondrial & metabolite \\
\hline XP_021757591 & cation $/ \mathrm{H}^{+}$antiporter 18-like & cation \\
\hline XP_021736780 & plastidic ATP/ADP-transporter-like & Misc \\
\hline XP_021738681 & V-type proton ATPase subunit a3-like & ATPases \\
\hline XP_021730105 & V-type proton ATPase subunit C-like & ATPases \\
\hline XP_021761683 & ATPase 11, plasma membrane-type-like & ATPases \\
\hline XP_021765334 & V-type proton ATPase subunit G 1-like & ATPases \\
\hline XP_021739675 & V-type proton ATPase catalytic subunit A & ATPases \\
\hline XP_021732700 & V-type proton ATPase catalytic subunit A-like & ATPases \\
\hline XP_021738896 & plasma membrane ATPase 4-like & ATPases \\
\hline XP_021762284 & V-type proton ATPase subunit $\mathrm{d} 2$ & ATPases \\
\hline XP_021765533 & V-type proton ATPase subunit B 2 & ATPases \\
\hline XP_021754298 & V-type proton ATPase subunit E-like & ATPases \\
\hline XP_021772280 & V-type proton ATPase subunit $\mathrm{H}$-like isoform $\mathrm{X} 2$ & ATPases \\
\hline XP_021714458 & mitochondrial outer membrane protein porin 2-like & Porin \\
\hline XP_021761841 & mitochondrial import receptor subunit TOM40-1-like & Porin \\
\hline XP_021758463 & mitochondrial outer membrane protein porin of $34 \mathrm{kDa}$ & Porin \\
\hline XP_021717525 & $\mathrm{K}^{+}$efflux antiporter 2 , chloroplastic-like & Potassium \\
\hline XP_021762166 & probable voltage-gated potassium channel subunit beta & Potassium \\
\hline XP_021753247 & monosaccharide-sensing protein 2-like & Sugar \\
\hline XP_021726328 & sugar carrier protein C-like & Sugar \\
\hline XP_021757156 & plastidic glucose transporter 4 -like & Sugar \\
\hline XP_021760460 & sucrose transport protein-like isoform $\mathrm{X} 1$ & Sucrose \\
\hline XP_021752898 & chloride channel protein CLC-b-like & anions \\
\hline XP_021739774 & ATPase ASNA1 homolog & anions \\
\hline XP_021772050 & ADP, ATP carrier protein 1 , mitochondrial-like & cation \\
\hline
\end{tabular}

\subsection{Differentially Abundant Proteins in Response to Salt Stress}

The GC proteome data were subjected to principal component analysis (PCA) as presented in the two-dimensional biplot to find out whether the GC proteome profiles of control and salt-treated plants differ from each other (Figure 2). In the PCA plot, PC1 accounts for the difference between the salt-treated and control treatments and PC2 shows differences between biological replicates. As shown in Figure 2, PC1 explained 55.3\% of the variance in the data, while PC2 captured the slight variance in protein expression profiles of GC. Hence, the separation of unstressed control and salt treatments into non-overlapping clusters suggests major differences between experimental treatments. 


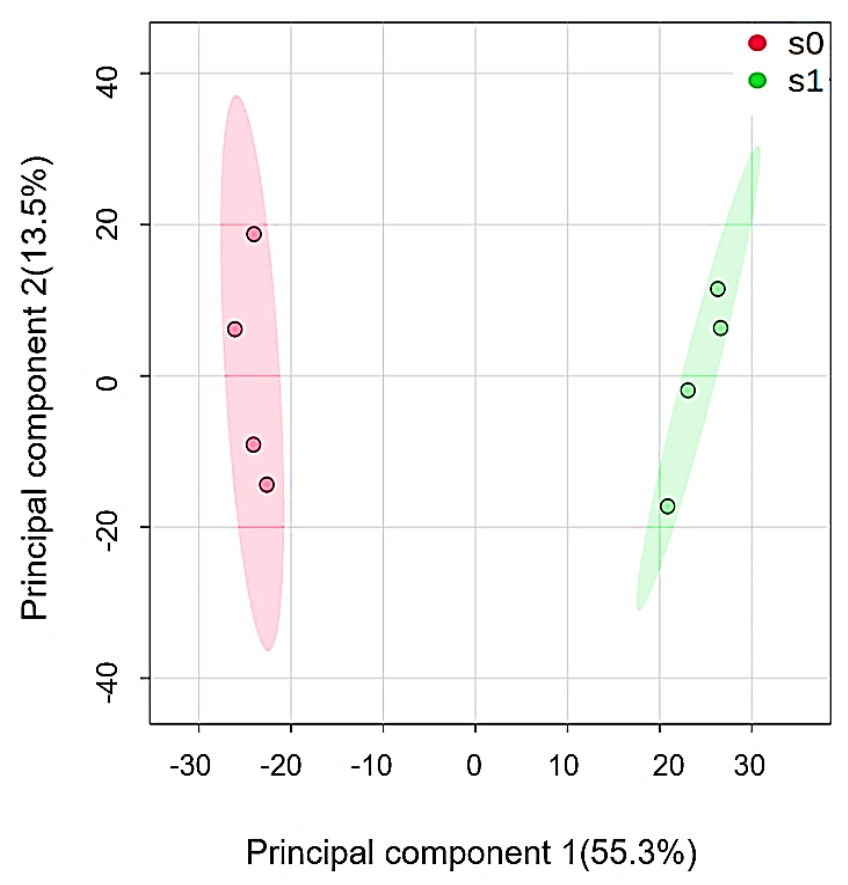

Figure 2. Principal component analysis (PCA) clustering based on GC proteome data under control and salt conditions. Proteomics analyses were performed with 4 replicates. S0 and S1 denote control and saline treatments, respectively.

To identify the differentially expressed proteins under saline conditions, a $t$-test using a false discovery rate FDR adjusted $p$-value $<0.05$ was performed and the data were analyzed in terms of fold-change relative to unstressed control (ratio values of treated/control). Proteins were considered differentially expressed between control and salt stress conditions if they met two criteria: the statistical criterion $(\mathrm{FDR}<0.05)$ and the biological measure (fold-change $>2$ ). Statistical significance of changes and deviations from control could be observed in a volcano plot (Figure 3). Based on these two measures, 387 proteins were differentially abundant under salt stress (185 upregulated and 202 downregulated).

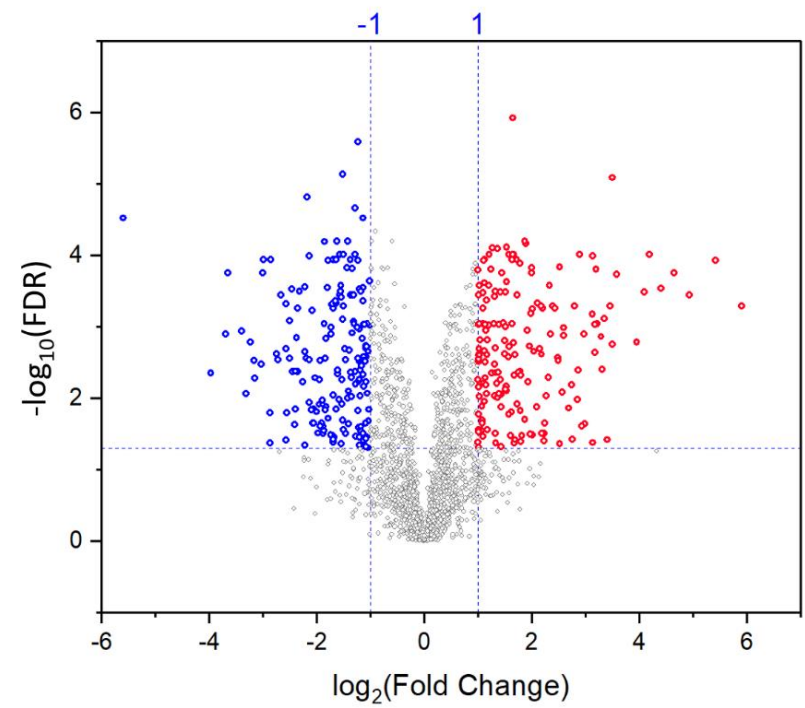

Figure 3. Volcano plot of differentially abundant proteins in the quinoa GCs in response to salt stress. Proteins with decreased and increased abundances (fold change $>2$, FDR $<0.05$ ) are illustrated as blue and red dots, respectively. Proteins with non-significant expressions and/or fold change of less than 2 are shown as grey dots. 
Heat maps were then used to provide an overview of abundance patterns of individual proteins in the whole proteome data (Figure 4). These heatmaps displayed similarities between biological samples in each treatment.
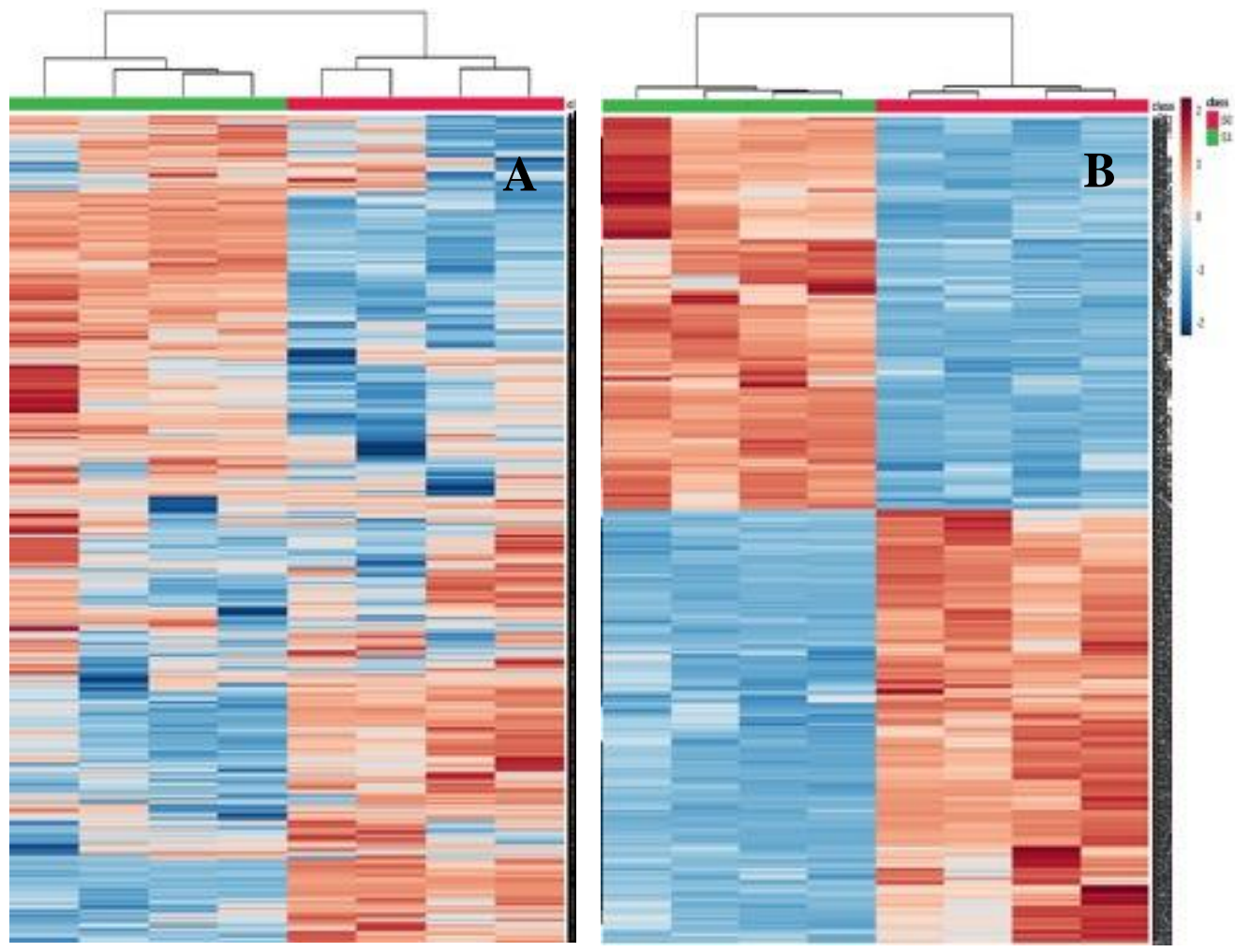

Figure 4. Heat maps based on Z-scores of protein abundance measurements demonstrating abundance patterns of individual proteins in the whole proteome (A) and differentially accumulated proteins (B). S0 and S1 denote control and saline treatments, respectively.

Sequence-based functional annotations of 185 upregulated and 202 downregulated proteins were then performed using Mercator (Figure 5) to identify possible functions of the differentially abundant proteins. The distribution of protein functions demonstrated that around $20 \%$ of proteins were not classified as any functional group. A large number of known functional proteins were classified as the following categories: protein synthesis, protein degradations, post-translational modification, RNA binding, regulation of transcription, DNA (DNA-binding, synthesis and repair), signaling, transport, biotic and abiotic stresses, development, lipid metabolism, cell wall and photosynthesis.

Several proteins involved in general stress responses (including those for osmotic and salt stresses) were found to be upregulated in GCs of quinoa following salinity treatment (Supplemental Table S1), including protein DR29B (50-fold), osmotin-like protein OSML13 (13-fold), polycystin-1, lipoxygenase, alpha-toxin, and triacylglycerol lipase (PLAT) domaincontaining protein 3-like (eight-fold), dehydrin early responsive to dehydration (ERD14) (eight-fold), and cationic peroxidase 1 (18-fold). Moreover, antioxidant molecules responsible for cell redox homeostasis such as glutaredoxin-C2- and thioredoxin H-type 1 (TRX) accumulated in salt-treated quinoa GCs. However, downregulation in the expression of the enzymatic antioxidant catalase (CAT) and L-ascorbate peroxidase 5 (APX) was observed in GC. In our study, PER2, PER5, and PER50 were decreased, while PER1 and PER4, PER12 and PER29 were highly increased in quinoa GCs in response to salt stress, suggesting that various members of a protein family might be expressed differently, suggesting potentially different functional roles. 


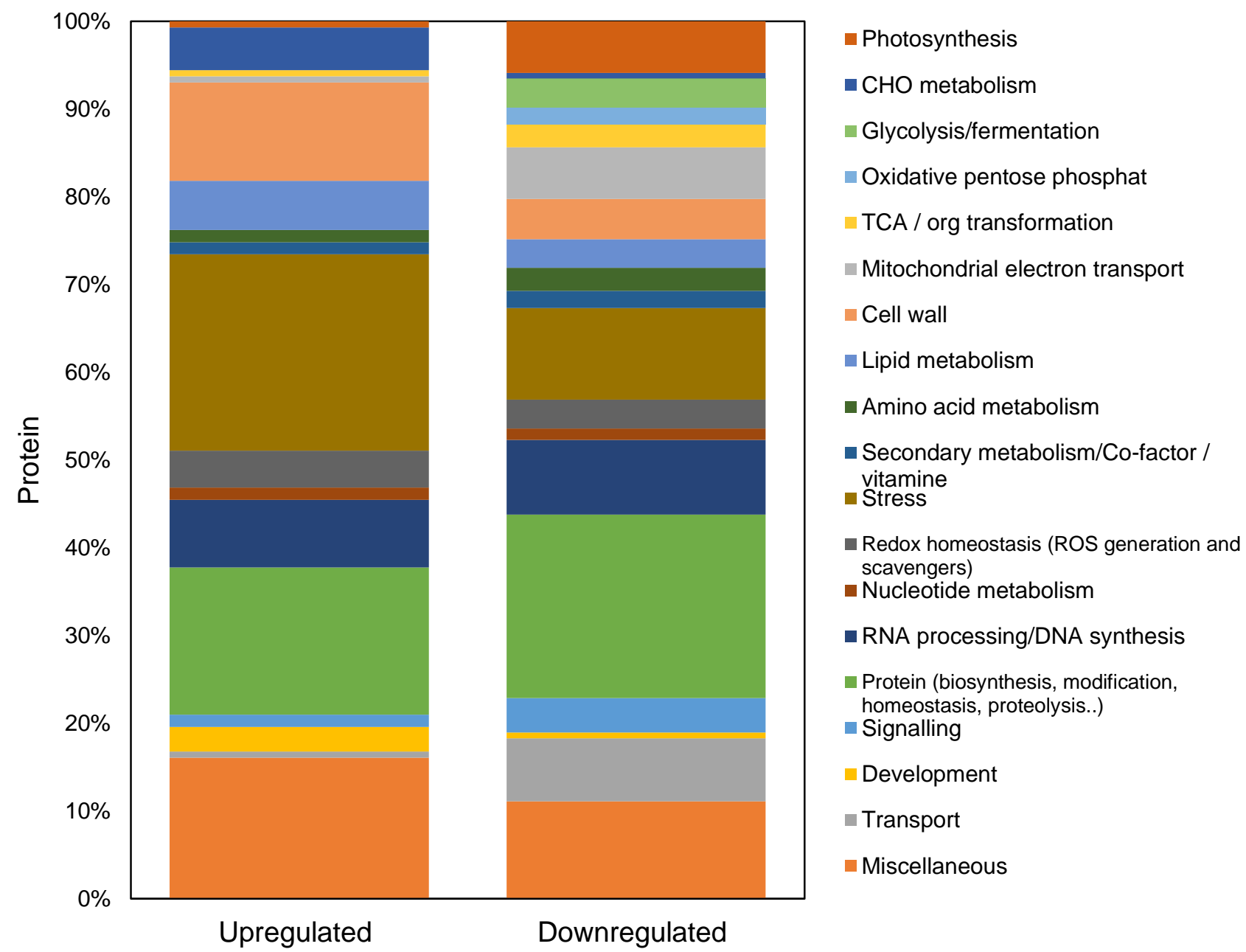

Figure 5. Comparison of differentially accumulated proteins in salt-responsive proteomes of quinoa GC. Upregulated (185 proteins) and downregulated (202 proteins) proteins identified from quinoa GCs have been classified into different categories based on their biological function according to MapMan terms. The $\mathrm{Y}$ axes indicate the $\%$ of proteins differentially accumulated in the quinoa GCs under $300 \mathrm{mM} \mathrm{NaCl}$. The up and downregulated proteins that were not assigned to a specific functional category were not included.

The metabolism of carbohydrates is rapidly modulated in response to environmental stresses. Glucan endo-1,3-beta-D-glucosidase and chitinase are hydrolases, which have been recognized as antifungal proteins, and were highly overexpressed in quinoa GCs under salt conditions (Supplemental Table S1). Glucan endo-1,3-beta-D-glucosidase (increased 27 -fold in saline conditions) is a pathogenesis-related (PR) protein, also reported to be associated with salt tolerance and ROS-scavenging in stressed plants [31]. High expression of this protein in GCs, especially in quinoa, may imply the importance of this protein in conferring salt tolerance in halophytes.

Salt stress has been shown to alter patterns of gene expression, potentially via modulation of transcription factors and other proteins, including those involved in alternative splicing. Alternative splicing is a process through which several transcripts and multiple forms of protein are produced from the same gene leading to an increase in proteome diversity. This post translational modification process is induced in plants under various stresses and results in quick adjustment of the function and abundance of key components of stress responses [32]. In this study, splicing factor U2af small subunit B-like is upregulated six-fold in quinoa GCs. This splicing factor, which belongs to a zinc finger $\mathrm{CCCH}$ domain-containing protein that is proposed to be important in the salt tolerance of plants, is upregulated six-fold in quinoa GCs [33]. NAP1-related protein X2, which 
belongs to a family of chaperones and is involved in DNA repair, is also critical under stress conditions [34]. This protein was also upregulated under salt stress (two-fold).

Salinity altered the physical properties of the GC wall. Cell wall-modifying enzymes such as acetyl- and methyl-esterifications of pectin were upregulated in GCs in our study. The acetyl- and methyl-esterifications of pectin are critical for the regulating mechanical properties of the cell wall [35]. Pectin methylesterification is essential for plant responses to environment stresses [36]. For example, PME34 regulates GC flexibility in response to heat stress. Glycine-rich cell wall proteins (GRPs) were upregulated in GCs of quinoa (18-fold). GRPs in the cell wall have 60-70\% glycine residues. GRPs generally are involved in the strengthening of biological structural systems or can support the development of expandable organs [37]. Our results are therefore consistent with increased mechanical strength in GCs exposed to salt stress.

\subsection{Proteins with a Role in Stomatal Movement}

Thirty-five proteins were found in this GC proteome study that have a role in stomatal movement (Table 4). For instance, accumulation of ABA receptors and PP2Cs proteins in the ABA signaling pathway can be found in the GC proteome. However, ABA receptor (PYL) showed no differential abundance in GCs of quinoa in response to salt stress while OST1 in GC was only marginally upregulated by salt stress (1.4-fold increase).

Table 4. Proteins with a direct role in GC function.

\begin{tabular}{|c|c|c|}
\hline Accession No & Name & Fold Change $\mathrm{NaCl} /$ Control \\
\hline XP_02174988 & abscisic acid receptor PYL2 & 1.1 \\
\hline XP_021736717 & phospholipase D alpha 1-like & $3.3 *$ \\
\hline XP_021739586 & GDPDL3-like & $2.1^{*}$ \\
\hline XP_021760770 & ricin B-like lectin EULS3 & $2.0^{*}$ \\
\hline XP_021754221 & MMK2-like & $1.6^{*}$ \\
\hline XP_021759066 & GDPDL3-like & $1.5 *$ \\
\hline XP_021738483 & OST1 & $1.3^{*}$ \\
\hline XP_021723531 & hexokinase-1-like & $0.9^{*}$ \\
\hline XP_021715572 & clathrin heavy chain 1-like & $0.8^{*}$ \\
\hline XP_021723433 & plasma membrane ATPase 4-like & $0.5^{*}$ \\
\hline XP_021761237 & calcium sensing receptor, chloroplastic-like & 0.5 * \\
\hline XP_021734330 & protein flowering locus t-like & $0.3^{*}$ \\
\hline XP_021776446 & protein thylakoid formation 1 & $0.3 *$ \\
\hline XP_021775775 & uncharacterized protein LOC110739633 & $0.2 *$ \\
\hline XP_021776385 & protein phosphatase $2 \mathrm{C}$ & 0.4 \\
\hline XP_021714641 & DNA-directed RNA polymerases II, IV and V & 2.5 \\
\hline XP_021721800 & BLUS1-like & 2.2 \\
\hline XP_021757551 & MMK2-like & 1.9 \\
\hline XP_021723484 & serine/threonine-protein kinase STY8-like & 1.8 \\
\hline XP_021760806 & carbonic anhydrase, chloroplastic & 1.7 \\
\hline XP_021740220 & cryptochrome-1-like isoform X3 & 1.4 \\
\hline XP_021753299 & phototropin-2-like & 1.3 \\
\hline XP_021731588 & glycine-rich RNA-binding, ABA-inducible protein & 1.1 \\
\hline XP_021774295 & phytochrome B-like & 1.1 \\
\hline XP_021742577 & translationally-controlled tumor protein homolog & 1.1 \\
\hline XP_021716254 & phototropin-1-like isoform $\mathrm{X} 1$ & 1.0 \\
\hline XP_021741723 & carbonic anhydrase, chloroplastic-like & 1.0 \\
\hline XP_021774801 & MMK1-like & 0.9 \\
\hline XP_021760799 & phospholipase D alpha 1-like & 0.9 \\
\hline XP_021758723 & chlorophyll a-b binding protein 3 , chloroplastic & 0.7 \\
\hline XP_021745518 & plasma membrane-associated cation-binding protein 1 & 0.7 \\
\hline XP_021731589 & glycine-rich RNA-binding protein-like & 0.7 \\
\hline XP_021723344 & phosphoglycerate mutase-like & 0.6 \\
\hline XP_021760744 & vesicle-associated membrane protein 711 & 0.6 \\
\hline XP_021769207 & clathrin heavy chain 1-like & 0.5 \\
\hline
\end{tabular}

* denotes a significant protein difference between control and salt stress (Student's $t$-test, $p<0.05$; fold change $>2.0$ ). 


\subsection{Protein Involved in Response to ABA in GC Proteome}

The ABA levels in plant tissue tend to elevate with exposure to salt or osmotic stress, indicating the contribution of $\mathrm{ABA}$ in stress signal transduction. In this study, ten proteins involved in response to ABA were found to be upregulated in quinoa GC (Figure 6) including LTI65 (50-fold), ASPG1 (4.1-fold), PLD (3.3-fold), $\alpha$ enzyme (21-fold), EDR14 (7.8-fold), LTP3 (8.1-fold), chitinase 1 (10.4-fold), Chit1 (5.8-fold), BFRUC4 (three-fold), PAP (22.2-fold).
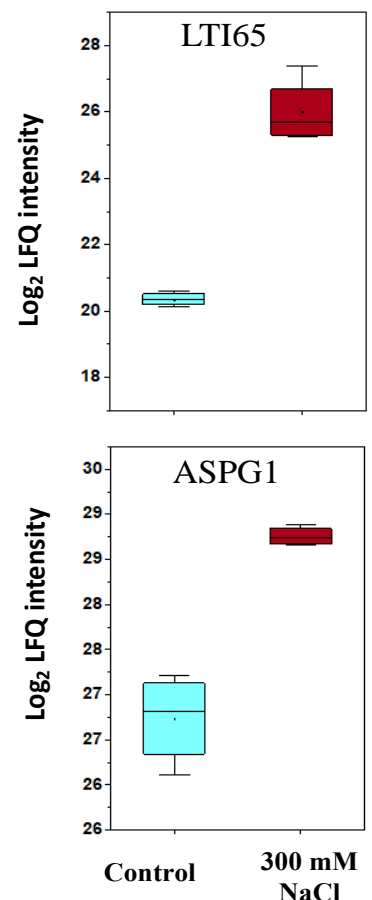
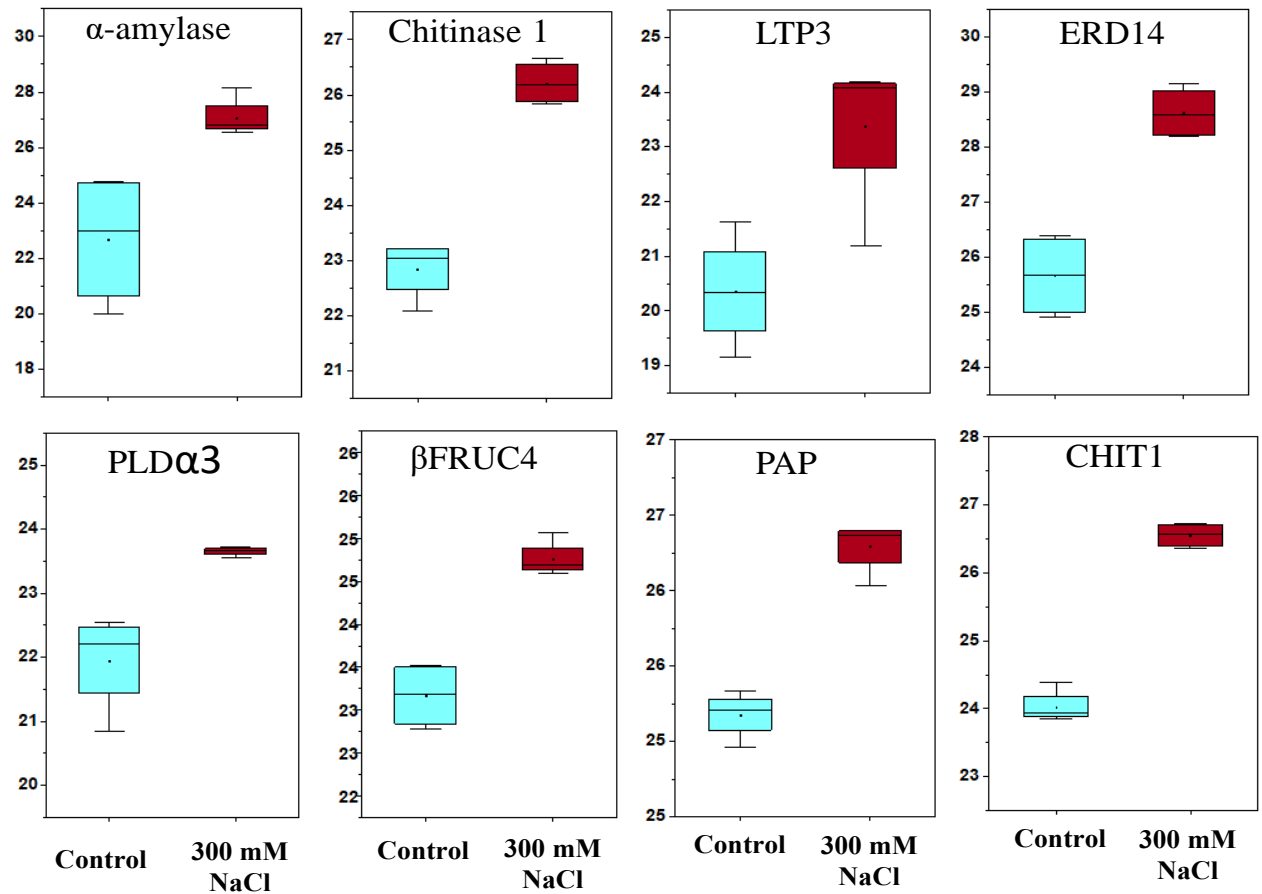

Figure 6. Proteins involved in ABA response, LTI65-low-temperature-induced $65 \mathrm{kDa}$ protein, $\alpha$-amylase-alpha-amylase, chitinase 1, LTP3-non-specific lipid-transfer protein 3, EDR14-dehydrin, ASPG1—protein aspartic protease in guard cell 1-like, PLD $\alpha 3$-phospholipase D, Bfruc4-acid beta-fructofuranosidase-like, PAP-plastid-lipid-associated protein, CHIT1-chitinase 1.

\subsection{The Effect of Sucrose, Tryptophan and L-Methionine on Stomatal Conductance}

In our study, sucrose synthase and two proteins related to biosynthesis of tryptophan and 5-methyltetrahydropteroyltriglutamate (involved in L-methionine biosynthesis) were accumulated in the GCs in response to salinity. To understand the physiological rationale behind this phenomenon, we studied effects of exogenous application of sucrose, tryptophan, and methionine on stomatal conductance (Figure 7). The results showed that application of sucrose, tryptophan, and L-methionine was associated with significant reduction in stomatal conductance. Stomatal conductance values were $1.10,1.39$ and $1.02 \mathrm{~mol} \mathrm{~m}^{-2} \mathrm{~s}^{-1}$ at the control conditions, which decreased to $0.62,0.93$ and $0.77 \mathrm{~mol} \mathrm{~m}^{-2} \mathrm{~s}^{-1}$ with the application of $30 \mathrm{mM}$ sucrose, tryptophan, and methionine, respectively (Figure 7). 

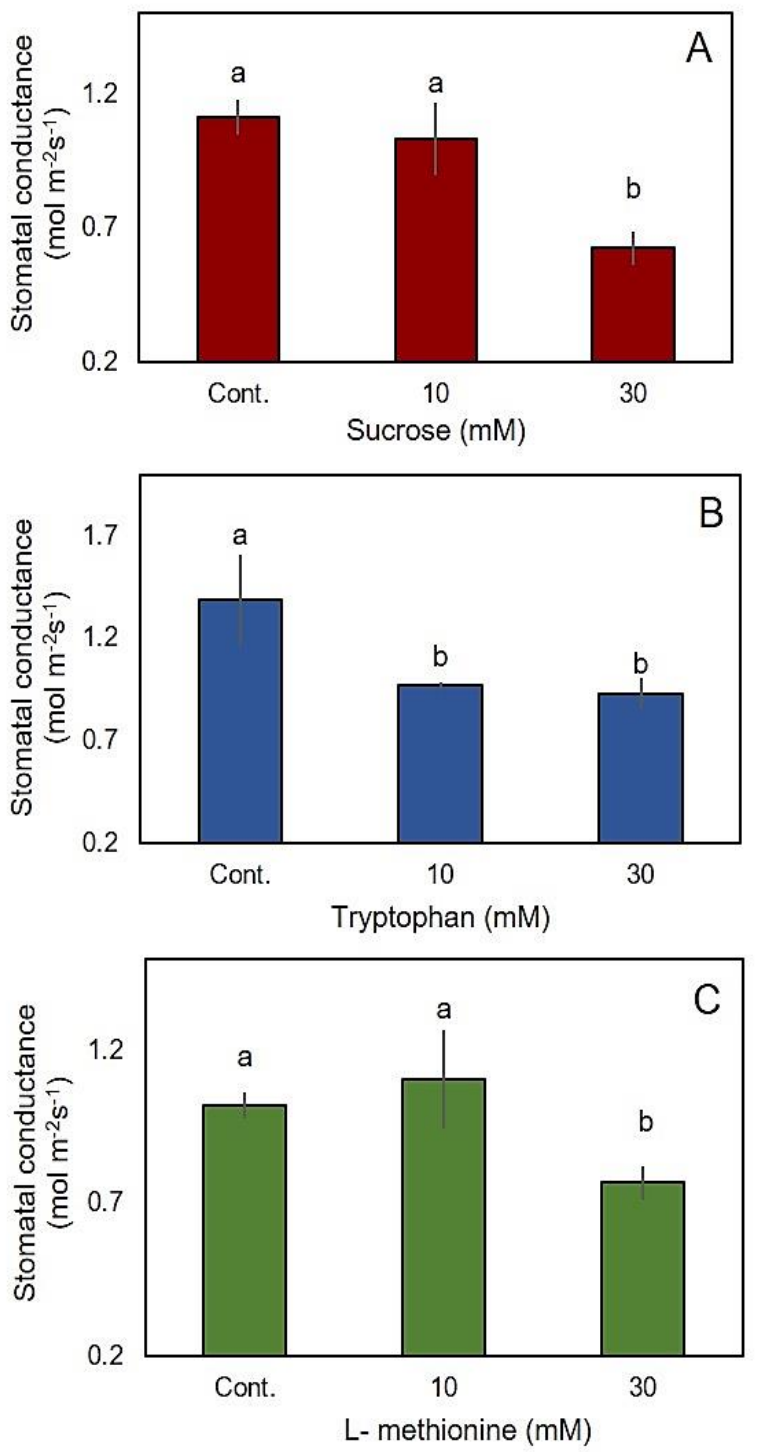

Figure 7. The effect of sucrose (A), tryptophan (B) and L-methionine (C) on stomatal conductance. Mean \pm SE $(n=5)$. Data labelled with different lower-case letters are significantly different at $p<0.05$ based on Tukey's test.

\subsection{The Effect of Salinity and Pepstatin A on Quinoa Growth and Stomatal Traits}

To understand the functionality of the aspartic proteinases, we blocked their action by spraying pepstatin A on the quinoa leaf for seven subsequent days in control and salttreated plants. Growth and stomatal trait responses of quinoa plants to salinity stress and pepstatin A are shown in Figure 8A-F. The fresh weight of salt-treated plants was reduced by $28 \%$ compared to untreated plants after three weeks of salt stress (Figure $8 \mathrm{~A}$ ). Stomatal density and size (length) in salt-grown plants was reduced by $23 \%$ and $37 \%$ compared to control conditions, respectively (Figure 8B,C). The impact of pepstatin A on stomatal density and size was statistically insignificant. Application of $2 \mu \mathrm{M}$ pepstatin A on leaf for a week did not affect the fresh weight of plants grown under control conditions while pepstatin A reduced the fresh weight of salt-grown plants by $14 \%$ (Figure $8 \mathrm{~A}$ ). 

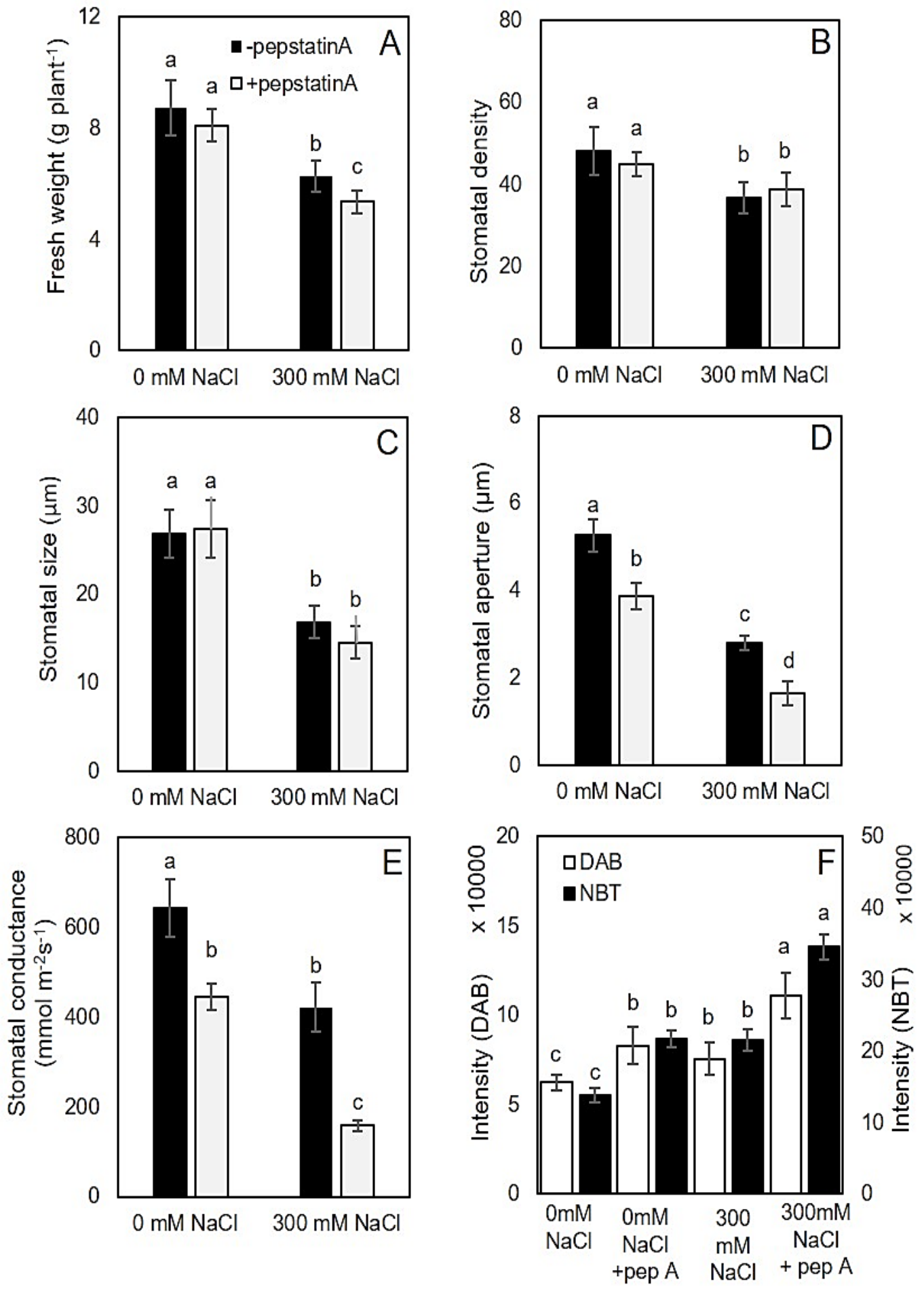

Figure 8. The effects of salinity stress and pepstatin A on different quinoa characteristics. (A) Fresh weight; (B) stomatal density; (C) stomatal size; (D) stomatal aperture; (E) stomatal conductance; (F) intensity of 3,3'-diaminobenzidine (DAB) and NBT staining in the GC as indicator of hydrogen peroxide and superoxide radical production. Data labelled with different lower-case letters (a-d) are significantly different at $p<0.05$ based on Tukey's test.

The stomatal aperture was lower in salt-treated plants than in control counterparts (Figure $8 \mathrm{D}$ ). It declined by $47 \%$ and $58 \%$ in untreated and treated plants by pepstatin A, respectively (significant at $p<0.05$ ). These decreases in stomatal aperture were accompanied by $34 \%$ and $64 \%$ decreases in stomatal conductance, compared to control plants (Figure 8E). 
The accumulation of superoxide radical $\left(\mathrm{O}^{2-}\right)$ and hydrogen peroxide $\left(\mathrm{H}_{2} \mathrm{O}_{2}\right)$ was analyzed using 3,3'-diaminobenzidine (DAB) and nitro blue tetrazolium (NBT) staining, respectively, in quinoa GCs. Plants grown under salinity stress were enriched in $\mathrm{O}^{2-}$ and $\mathrm{H}_{2} \mathrm{O}_{2}$. Application of pepstatin A resulted in higher accumulation of $\mathrm{O}^{2-}$ and $\mathrm{H}_{2} \mathrm{O}_{2}$ in the GCs and higher ROS accumulation was observed in chloroplast (Figures $8 \mathrm{~F}$ and 9).

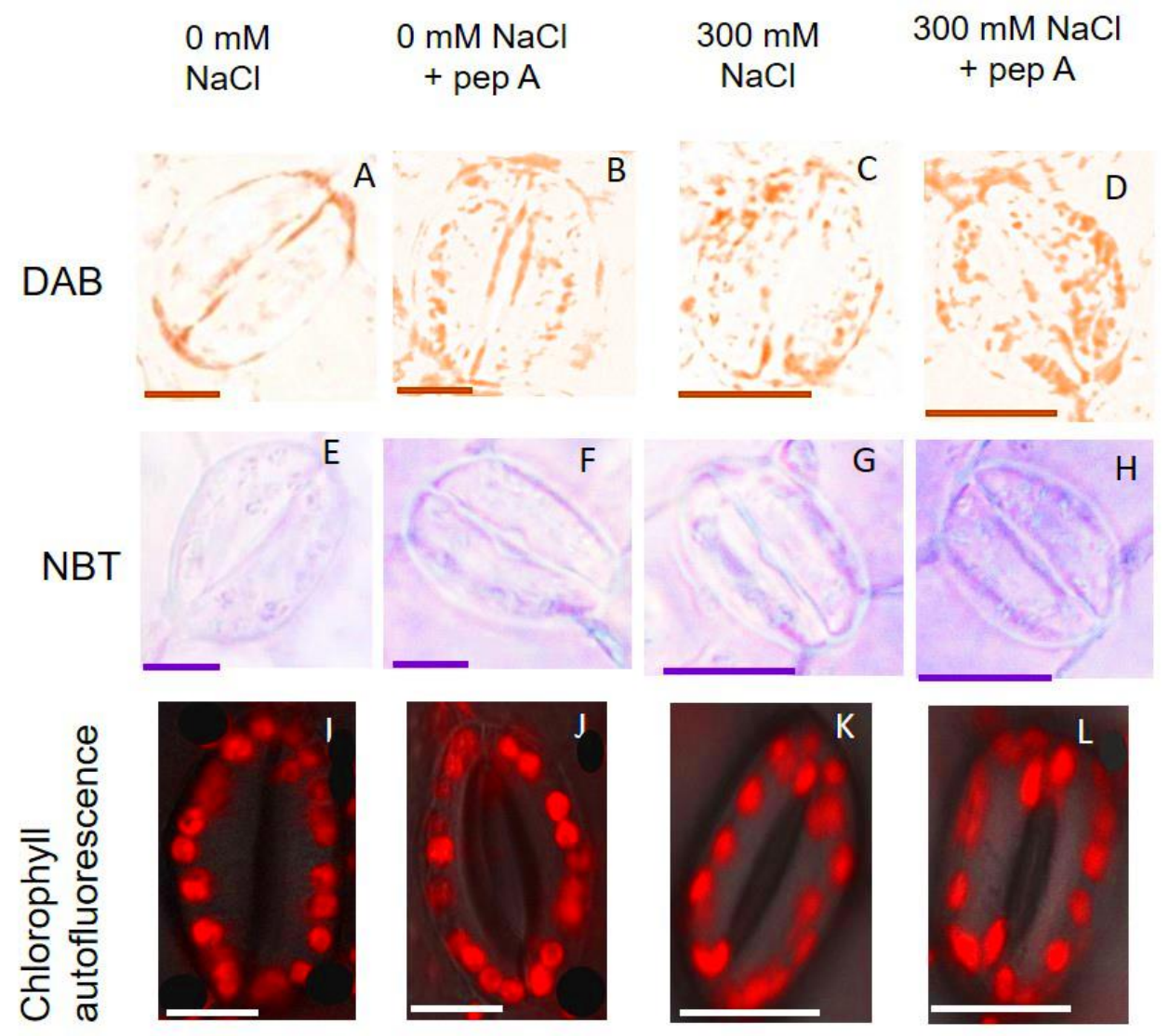

Figure 9. Hydrogen peroxide and superoxide radical generation and chlorophyll autofluorescence in GCs of quinoa in response to salt stress and pepstatin A. (A-D): 3,3'-Diaminobenzidine (DAB) staining to detect $\mathrm{H}_{2} \mathrm{O}_{2}$ in GCs. (E-H) Nitro blue tetrazolium (NBT) staining to detect superoxide radicals in GCs. Chlorophyll autofluorescence in GCs (I-L) was visualized using a laser scanning confocal microscope (LEICA SMD FLCS) at an excitation wavelength of $488 \mathrm{~nm}$ and chlorophyll autofluorescence was detected between $629 \mathrm{~nm}$ and $697 \mathrm{~nm}$. Bar $=10 \mu \mathrm{m}$.

\section{Discussion}

A comparison of differentially abundant proteins in quinoa and sugar beet [23] displayed that only $5 \%$ of up and downregulated proteins in quinoa are shared with those in sugar beet. Aspartic protease and non-specific lipid-transfer proteins showed enhanced abundance while catalase and cationic peroxidase showed lower abundances in GCs of both salt-treated plants. Lower levels of catalase may be necessary in the guard cells in saline conditions as $\mathrm{H}_{2} \mathrm{O}_{2}$ functions as a signaling molecule in the guard cell and induces stomatal closure in response to high salinity stress. Moreover, some proteins involved in mitigation of oxidative stress such as L-ascorbate oxidase were presented at elevated levels under non-stress conditions in both species, suggesting that the constitutive accumulation of those proteins in the guard cells of the halophyte quinoa and the salt-tolerant sugar beet can confer augmented tolerance to GCs of both species when exposed to salt stress. The salinity treatment in quinoa exhibited the larger number of differentially abundant proteins compared with sugar beet, suggesting their possible mechanistic role to confer salt-tolerance in quinoa. When differentially abundant proteins in salt-responsive proteomes of guard cells of quinoa and sugar beet were compared based on their biological 
function, the largest single group of proteins present in both species were those involved in protein biogenesis and disposal (e.g., ribosomal subunits, molecular chaperones, and proteasomal subunits) and the next most abundant protein categories were identified as "stress". However, the top proteins according to overall abundance in sugar beet and quinoa GCs were dissimilar and they were different from what is previously reported in the other species such as Arabidopsis [19].

\subsection{Most Abundant Proteins in the GCs Isolated from Quinoa}

Rubisco activase was the most abundant protein in quinoa GCs. This is not surprising as Rubisco activase in some halophytes such as Suaeda salsa and Eutrema halophila is present at higher amounts compared to glycophytes [38]. Furthermore, it has been reported that the promotor region of the Rubisco activase gene is enriched in stress responsive elements including two for temperature, three for dehydration and five for light responses, which means Rubisco activase is a light- and stress-regulated gene [24].

In addition to Rubisco activase, a GDSL motif containing esterases/lipases was found to be among the most highly abundant proteins in quinoa GCs. Previous studies have found that the degree of stomatal aperture in response to low $\mathrm{CO}_{2}$ corresponds to increased levels of GDSL esterase/lipases [21]. Furthermore, there is some evidence to suggest involvement of this protein in the salt tolerance mechanism, as a gene belonging to the GDSL-motif lipase family was found to confer enhanced salt and pathogen resistance in Arabidopsis [39].

ABP19 was also an abundant protein in quinoa GCs. ABP19 is a receptor for a hormone auxin that is involved in stomatal patterning and development [40]. Auxin has been proposed to be involved in the modulation of $\mathrm{K}^{+}$channel in the GC [41]. In Paphiopedilum tonsum, ABP decreased GC cytoplasmic $\mathrm{pH}$ and induced stomatal opening [42].

\subsection{Photosynthesis in the GCs}

Analysis of GC proteins demonstrated that photosynthesis was among the top 10 GO terms in the GC proteome (Supplemental Table S1). Photosynthesis in GCs has been a controversial topic for many years. Although Rubisco and other enzymes for carbon reduction are both present and active in GCs, and the emerging consensus is that photosynthesis does takes place in GCs; however, the role of GC photosynthesis in relation to stomatal behavior is still unclear. A recent experiment on transgenic Arabidopsis [43] with targeted chlorophyll deficiency in GCs has found that GCs are thin and flaccid suggesting that photosynthesis is essential for GC turgor. Another recent study [44] has demonstrated that photosynthesis in GC is necessary for ABA signaling. Photosynthetic electron transport in GCs generates ROS, which act as signaling molecules in stomatal closure induced by ABA.

\subsection{Stress and Defence-Related Proteins}

The high upregulation of dehydrins (LTI65 and ERD14) in salt-treated quinoa GCs implies dehydrin proteins play a role in stomata of halophytes such as quinoa under saline conditions. Early responsive to dehydration (ERD14) belongs to the dehydrin family of proteins containing highly hydrophilic and charged residues that allow a highly flexible structure. They contribute to multiple functions as protecting macromolecular and stabilizing proteins and are the best representative of late embryogenesis abundant (LEA) proteins [45]. In addition to functioning as a chaperone protein, they also act as osmoticum being able to attract water towards the cell to adjust osmotic potential and maintain water status [46].

Polycystin-1, lipoxygenase, alpha-toxin, and triacylglycerol lipase (PLAT) domaincontaining protein is generally expressed in vascular tissue and GCs. The levels of this protein increased under salt and ABA stresses [47]. This protein binds to bZIP transcription factors AREB/ABFs that mediate the ABA signaling pathway [47]. ASPG1, a GC specific gene that encodes aspartic protease, was found to increase four-fold in response to salinity. 
This protein is highly expressed in tolerant genotypes but highly repressed in sensitive ones, indicating a potential role in osmotic stress regulation by osmotic adjustment [48].

In this study, ten proteins involved in response to ABA were found to be upregulated in quinoa GC (Figure 6). Among them, LTI65 is involved in the abscisic acid-activated signaling pathway, as the promoter region of this gene contains two ABA-responsive elements (ABREs).

PLD $\alpha$ enzyme is activated by ABA and produces phosphatidic acid (a signaling molecule), which induces stomatal closure [49]. Plastid-lipid-associated proteins that are lipid-binding physically bind to ABI2 as a key regulator of ABA-mediated response. Overexpression of protein aspartic protease in GCs has been associated with an increase in ABA sensitivity in the stomatal closure [50].

\subsection{Sucrose, Tryptophan and L-Methionine Induced Stomatal Closure}

In the current study, many proteins related to the sucrose/starch metabolism pathway were upregulated in the GC in response to salt stress in quinoa (Supplemental Table S1). The abundance of alpha-amylase 1 that is involved in starch breakdown increased by 21 -fold under salt stress.

Regulation of stomatal movements by apoplastic sucrose has been a matter of debate [51]. Early studies proposed that sucrose act as an osmolyte that can induce stomatal opening [52]. However, recent studies using functional, physiological, and molecular evidence have proven that sugars including sucrose within the GCs stimulate stomatal closure through involvement of hexokinase $[51,53,54]$. Hexokinases serve as a sugar-sensing enzyme in plants and overexpression of this gene has been accompanied with enhanced sugar sensing effects, such as a lower photosynthesis rate, and energy supply. In the GCs, overexpression of this gene in the presence of externally added sucrose resulted in significantly lower stomatal aperture in tomato and Arabidopsis [53]. It was shown that hexokinase can initiate an abscisic acid stomatal closure pathway in the GCs [51]. Our proteomics data showed that degradation of starch and production of sucrose have been increased in the GCs in response to $300 \mathrm{mM} \mathrm{NaCl}$. In our recent work, quinoa has displayed a reduced photosynthesis rate under $300 \mathrm{mM}$ salt stress [55], suggesting that sucrose generation in GCs under salt stress is to coordinate photosynthesis with transpiration and reduce water loss.

In our proteomic study, two proteins related to biosynthesis of tryptophan and 5methyltetrahydropteroyltriglutamate (involved in L-methionine biosynthesis) were accumulated in the GCs by salinity. Accumulation of some amino acids as compatible solute for supporting the balance of water potential in cytosol with vacuole and apoplast in response to salt stress has been reported [56]. In our study, the application of tryptophan and L-methionine was associated with reduced stomatal aperture and conductance, suggesting the involvement of other pathways such as the modulation of channels by amino acids. In an earlier study on barley root under saline conditions, application of amino acids resulted in mitigation of the $\mathrm{NaCl}$-induced potassium efflux for most amino acids including tryptophan and methionine [57]. In contrast, in GCs, exogenous tryptophan, but not methionine, increased $\mathrm{K}^{+}$efflux leading to stomatal closure in Vicia faba [58] while L-methionine modulates $\mathrm{Ca}^{2+}$ channels to regulate stomatal aperture. It has been suggested that L-methionine activates the calcium channels in GCs, leading to elevation of cytosolic calcium and generation of reactive oxygen species, and stomatal closure [59].

\subsection{Aspartic Proteinases Are Important in Mitigating Oxidative Stress of GCs}

In this study, eight proteins from the aspartic proteinase family were highly upregulated by salt in the quinoa GCs, including four aspartic proteinase CDR1-like proteins (10.3, 11.3, 18.0 and 22.7-fold) and three aspartic proteinase A1-like (2.4, 10.4 and 10.5- fold). Aspartic proteinase in guard cell-1 encoded by a guard-cell specific gene (ASPG1 gene) was also accumulated 4.1-fold in GCs of salt-treated quinoa plants compared to control. 
Aspartic proteinases are distributed throughout the plant kingdom and have been implicated in many biological processes such as protein degradation, protein processing, stress responses, and programmed cell death [60,61]. For example, the overexpression of the ASPG1 gene has been reported to be involved in the drought avoidance through the ABA signal transduction pathway in Arabidopsis [50]. VlAP17 is also another aspartic protease gene that is upregulated in Arabidopsis leaves in response to osmotic stress [62].

In our study, the aspartic proteinases that were upregulated in response to salt stress in GCs belong to the pepsin family whose activities have been proven to be inhibited by pepstatin A $[63,64]$. The results of the blockage of aspartic proteinases by pepstatin A showed that stomatal conductance and aperture were dramatically reduced in pepstatin A-treated plants for both control and salt-stressed plants. Oxidative status analysis of GCs indicated that a higher level of reactive oxygen species was accumulated in the GCs when the activity of the aspartic proteinases was inhibited by pepstatin A. These results indicate that the aspartic protease activity is required for the mitigating salt-induced ROS production in the GCs in salt-affected plants. In Arabidopsis, aspartic proteinases have been suggested to play a role in protecting the integrity of plasma membrane by increasing levels of antioxidants compounds [62]. Overexpression of aspartic proteinase genes enhanced ABA sensitivity in GCs, and resulted in elevated adaptive drought resistance in Arabidopsis [50].

It has been proposed that ROS function as signaling molecules to promote stomatal closure in response to various biotic and abiotic stress conditions [65]. In our previous study on sugar beet GCs [23], a higher concentration of $\mathrm{H}_{2} \mathrm{O}_{2}$ was detected in the GCs under saline conditions compared to control, which was mitigated by ascorbic acid and resulted in higher stomatal conductance and slower response of stomata to dark conditions. In the present study, inhibition of aspartic proteinases impaired stomatal opening due to excessive accumulation of oxidant molecules in the GCs. Aspartic proteinases may control GC ROS homeostasis and allow stomatal opening.

Aspartic proteinases and many proteins whose accumulations have been altered in response to salinity stress in the GCs might be a source of novel candidates with critical roles in salinity tolerance and could be a target for further experiments. Genome sequences of quinoa have been recently published [66,67], which can effectively help in identifying genes related to salinity stress tolerance in this species.

\section{Materials and Methods}

\subsection{Growth Conditions and GC Preparation}

Six seeds of quinoa were planted in a temperature-controlled glasshouse $\left(22^{\circ} \mathrm{C}, 70 \%\right.$ relative humidity, and 12/12 h day/night) at the University of Tasmania. Plants were grown in 8 inch diameter pots filled with potting mix containing $90 \%$ composted pine bark; $5 \%$ coarse sand; $5 \%$ coco peat; gypsum $\left(1 \mathrm{~kg} \cdot \mathrm{m}^{-3}\right)$; dolomite $\left(6 \mathrm{~kg} / \mathrm{m}^{3}\right)$; ferrous sulphate $\left(1.5 \mathrm{~kg} \cdot \mathrm{m}^{-3}\right)$; Osmoform Pre-Mix $\left(1.25 \mathrm{~kg} \cdot \mathrm{m}^{-3}\right)$ and slow-released fertilizer, Scotts Pro $\left(3 \mathrm{~kg} \cdot \mathrm{m}^{-3}\right)$. Salt stress was imposed 3 weeks after planting by adding $300 \mathrm{mM} \mathrm{NaCl}$ to irrigation water over a period of 3 weeks. GC-enriched epidermal peels were prepared as it was previously described $[23,68]$. Briefly, fully expanded leaves of well-watered 3-4 week-old quinoa were grinded in a Grindomix blender with a basic solution and crushed ice, then it was passed through a nylon mesh and rinsed with ice-cold distilled water. The entire process was repeated four times. Isolated GCs-enriched fragments were first examined under the microscope to confirm that no contamination of mesophyll fragments or vascular particles were present. The samples were snap-froze in liquid nitrogen and were kept at $-80^{\circ} \mathrm{C}$ until they were used for protein extraction.

\subsection{Label-Free Quantitative (LFQ) Proteomic Analysis of Quinoa GCs:}

Protein samples from four biological replicates per treatment were extracted essentially as published elsewhere [23]. Following homogenization by grinding in liquid nitrogen, proteins were precipitated using TCA-acetone containing $0.07 \%(v / v)$ 2-mercaptoethanol, followed by two acetone washes and resuspension in a denaturation buffer ( $7 \mathrm{M}$ urea etc). Pro- 
tein concentrations were estimated using the Pierce $660 \mathrm{~nm}$ spectrophotometric assay. Following reduction and alkylation by the standard methods, protein digests ( $30 \mu \mathrm{g} / \mathrm{sample})$ were prepared using the SP3 method for sample clean-up and digestion with $1.2 \mu \mathrm{g}$ MS grade trypsin/LysC [69]. Peptide samples of about $\sim 1 \mu \mathrm{g}$ were analyzed by LC/MS using an Ultimate 3000 RSLCnano and Q-Exactive HF (Thermo Scientific) as described earlier [23]. Raw DDA-MS) files were analyzed using the MaxQuant platform for LFQ proteomics (version 1.6.5.0) utilizing the Andromeda search engine to match MS/MS spectra against the NCBI Chenopodium quinoa (wild) proteome database $(63,475$ entries downloaded on $20 / 10 / 18$ ). Search parameters were set to default values for Orbitrap mass spectrometry using a $1 \%$ FDR for both peptide-spectrum matches and protein identification. Protein groups identified either as potential contaminants (prefixed with CON_), identified by modified site only, by reverse database matching or on the basis of a single matching peptide were removed.

\subsection{Determination of Relative Protein Abundance and Statistical Analysis}

We utilized MaxLFQ, the MaxQuant algorithm for peptide intensity determination and normalization, using pair-wise comparison of unique and razor peptide intensities and a minimum ratio count of 2 . The protein group output files generated by MaxQuant analysis were processed as follows: the normalized label-free quantification (LFQ) intensity values, MS/MS counts and the numbers of razor and unique peptides for each of the identified proteins were imported into Perseus software version 1.5.031 (http:/ / perseusframework.org/). Protein groups identified either as potential contaminants (prefixed with CON_), identified by modified site only, by reverse database matching or on the basis of a single matching peptide were removed. LFQ intensity values were then log2transformed and then a filter was applied to include only proteins detected in a minimum of $70 \%$ of the samples. Missing values were replaced with random intensity values for lowabundance proteins based on a normal distribution of protein abundances using default MaxQuant parameters.

\subsection{Stomatal Conductance in Plants Treated with Sucrose, Tryptophan, and L-Methionine}

The effects of 10 and $30 \mathrm{mM}$ exogenously applied sucrose tryptophan and L-methionine on stomata aperture were studied by spraying the above agents on the leaf and measuring stomatal conductance two hours later under normal light in the glasshouse using a Li-Cor 6400 gas analyzer system (Lincoln, NE, USA).

\subsection{Exogenous Application of Pepstatin A}

Quinoa plants were grown for 3 weeks under $300 \mathrm{mM}$ salt and control conditions. Pepstatin A was dissolved in 100\% ethanol and was applied to leaves at a final concentration of $2 \mathrm{mM}$. After a week, fresh weight and stomatal parameter intensity of DAB and NBT staining in the GCs as an indicator of hydrogen peroxide and superoxide radical production were then determined. A SC-1 leaf porometer was used for stomatal conductance in control and pepstatin A-treated plants.

\subsection{In Situ Detection of $\mathrm{O}_{2}^{-}$and $\mathrm{H}_{2} \mathrm{O}_{2}$ in GCs and Imaging}

Hydrogen peroxide in GCs was detected using 3,3'-diaminobenzidine (DAB) staining. For this purpose, leaves from control and salt-treated plants were incubated in DAB solution $\left(1 \mathrm{mg} \cdot \mathrm{mL}^{-1} \mathrm{DAB}\right.$, and $50 \mathrm{mM}$ Tris-acetate buffer $\left.(\mathrm{pH}=5)\right)$. Vacuum-infiltrating was applied for $10 \mathrm{~min}$ in the dark. Then, the samples were kept on the shaker overnight at $75 \mathrm{rpm}$ shaking speed. Superoxide radical $\left(\mathrm{O}^{2-}\right)$ was detected using nitro blue tetrazolium (NBT). The leaf samples were incubated in $0.1 \mathrm{mg} \mathrm{mL}^{-1} \mathrm{NBT}$ solution prepared in $25 \mathrm{mM}$ HEPES buffer $(\mathrm{pH}=7.6)$ for four hours. The stained samples were then de-stained using an ethanol:glycerol:acetic acid (3:1:1) solution two times before visualizing in light microscopy. The washing process for DAB staining and NBT staining was carried out under $90{ }^{\circ} \mathrm{C}$ and $65^{\circ} \mathrm{C}$, respectively. Chlorophyll autofluorescence was visualized using a laser scanning 
confocal microscope (LEICA SMD FLCS) at an excitation wavelength of $488 \mathrm{~nm}$ and chlorophyll autofluorescence was detected between $629 \mathrm{~nm}$ and $697 \mathrm{~nm}$.

\subsection{Statistical Analyses}

Data were analyzed using IBM SPSS Statistics software, version 27 (IBM Corp., Armonk, NY, USA). Statistical significance was determined by one-way ANOVA analysis based on Tukey's test. The differences between means were considered statistically significant as P-values were less than 0.05 .

\section{Conclusions}

This study demonstrated that salinity stress significantly altered the protein profile of quinoa GCs where the abundance of many proteins including signaling molecules, enzyme modulators, transcription factors and oxidoreductases was changed. Furthermore, many proteins involved in osmotic or salinity stress as well as in response to ABA were found to be highly abundant or upregulated in quinoa GC following salinity treatment. Additionally, exogenous application of sucrose and amino acids (tryptophan and L-methionine) resulted in reduced stomatal aperture and conductance, suggesting that it could be advantageous for plant adaptation to salt stress. Inhibition of aspartic proteinases impaired stomatal opening due to excessive accumulation of ROS in the GCs, suggesting the important role of aspartic proteinases in GC ROS homeostasis and stomata movements.

Supplementary Materials: Supplementary Materials can be found at https://www.mdpi.com/1422 $-0067 / 22 / 1 / 428 /$ s1.

Author Contributions: F.R. has performed experiments and prepared the paper draft. A.K.-P. contributed to data collection. L.L. contributed to bioinformatic analysis. R.W. acquired the proteomics data. L.S., A.T. and M.Y. critically assessed the manuscript. Z.C. and R.H. conceived the concept and revised the MS. H.Z. and S.S. designed the experiments and wrote the paper. The final version of the MS was approved by all authors. All authors have read and agreed to the published version of the manuscript.

Funding: This work was supported by China's National Science Foundation (project 31870249), the National Distinguished Expert Project (WQ20174400441), and Australian Research Council (DP170100430) grants to Sergey Shabala.

Institutional Review Board Statement: Not applicable.

Informed Consent Statement: Not applicable.

Data Availability Statement: Not applicable.

Conflicts of Interest: The authors have no conflict of interest to declare.

$\begin{array}{ll}\text { Abbreviations } \\ \text { ABA } & \text { abscisic acid } \\ \text { DAB } & 3,3^{\prime} \text {-diaminobenzidine } \\ \text { FDR } & \text { False Discovery Rate } \\ \text { GC } & \text { guard cells } \\ \text { KEGG } & \text { Kyoto Encyclopedia of Genes and Genomes } \\ \text { NBT } & \text { nitro blue tetrazolium } \\ \text { NCBI } & \text { National Center for Biotechnology Information } \\ \text { ROS } & \text { Reactive oxygen species }\end{array}$

\section{References}

1. Ache, P.; Bauer, H.; Kollist, H.; Al-Rasheid, K.A.; Lautner, S.; Hartung, W.; Hedrich, R. Stomatal action directly feeds back on leaf turgor: New insights into the regulation of the plant water status from non-invasive pressure probe measurements. Plant J. 2010, 62, 1072-1082. [CrossRef] [PubMed]

2. Hetherington, A.M.; Woodward, F.I. The role of stomata in sensing and driving environmental change. Nature 2003, 424, 901-908. [CrossRef] 
3. Lawson, T.; Blatt, M.R. Stomatal size, speed, and responsiveness impact on photosynthesis and water use efficiency. Plant Physiol. 2014, 164, 1556. [CrossRef] [PubMed]

4. Mickelbart, M.V.; Hasegawa, P.M.; Bailey-Serres, J. Genetic mechanisms of abiotic stress tolerance that translate to crop yield stability. Nat. Rev. Genet. 2015, 16, 237-251. [CrossRef] [PubMed]

5. Liu, Y.; Kong, Z.; Liu, J.; Zhang, P.; Wang, Q.; Huan, X.; Li, L.; Qin, P. Non-targeted metabolomics of quinoa seed filling period based on liquid chromatography-mass spectrometry. Food Res. Int. 2020, 137, 109743. [CrossRef] [PubMed]

6. Chaves, M.M.; Costa, J.M.; Zarrouk, O.; Pinheiro, C.; Lopes, C.M.; Pereira, J.S. Controlling stomatal aperture in semi-arid regions-The dilemma of saving water or being cool? Plant Sci. 2016, 251, 54-64. [CrossRef] [PubMed]

7. Zhang, Y.J.; Li, D.H.; Zhou, R.; Wang, X.; Dossa, K.; Wang, L.H.; Zhang, Y.X.; Yu, J.Y.; Gong, H.H.; Zhang, X.R.; et al. Transcriptome and metabolome analyses of two contrasting sesame genotypes reveal the crucial biological pathways involved in rapid adaptive response to salt stress. BMC Plant Biol. 2019, 19, 66. [CrossRef]

8. Zhu, J.K. Salt and drought stress signal transduction in plants. Annu. Rev. Plant Biol. 2002, 53, 247-273. [CrossRef]

9. Flowers, T.J.; Colmer, T.D. Plant salt tolerance: Adaptations in halophytes. Ann. Bot. 2015, 115, 327-331. [CrossRef]

10. Hedrich, R.; Shabala, S. Stomata in a saline world. Curr. Opin. Plant Biol. 2018, 46, 87-95. [CrossRef]

11. Kiani-Pouya, A.; Rasouli, F.; Bazihizina, N.; Zhang, H.; Hedrich, R.; Shabala, S. A large-scale screening of quinoa accessions reveals an important role of epidermal bladder cells and stomatal patterning in salinity tolerance. Environ. Exp. Bot. 2019, 168, 103885. [CrossRef]

12. Takemori, A.; Nakashima, T.; Omura, H.; Tanaka, Y.; Nakata, K.; Nonami, H.; Takemori, N. Quantitative assay of targeted proteome in tomato trichome glandular cells using a large-scale selected reaction monitoring strategy. Plant Methods 2019, 15, 40. [CrossRef] [PubMed]

13. Barkla, B.J.; Vera-Estrella, R.; Raymond, C. Single-cell-type quantitative proteomic and ionomic analysis of epidermal bladder cells from the halophyte model plant Mesembryanthemum crystallinum to identify salt-responsive proteins. BMC Plant Biol. 2016, 16, 110. [CrossRef] [PubMed]

14. Geilfus, C.M.; Lan, J.; Carpentier, S. Dawn regulates guard cell proteins in Arabidopsis thaliana that function in ATP production from fatty acid beta-oxidation. Plant Mol. Biol. 2018, 98, 525-543. [CrossRef] [PubMed]

15. Zhu, M.M.; Dai, S.J.; McClung, S.; Yan, X.F.; Chen, S.X. Functional differentiation of Brassica napus guard cells and mesophyll cells revealed by comparative proteomics. Mol. Cell Proteomics 2009, 8, 752-766. [CrossRef] [PubMed]

16. Adolf, V.I.; Jacobsen, S.-E.; Shabala, S. Salt tolerance mechanisms in quinoa (Chenopodium quinoa Willd.). Environ. Exp. Bot. 2013, 92, 43-54. [CrossRef]

17. Lopez-Marques, R.L.; Norrevang, A.F.; Ache, P.; Moog, M.; Visintainer, D.; Wendt, T.; Osterberg, J.T.; Dockter, C.; Jorgensen, M.E.; Salvador, A.T.; et al. Prospects for the accelerated improvement of the resilient crop quinoa. J. Exp. Bot. 2020, 71, 5333-5347. [CrossRef]

18. Shabala, S. Learning from halophytes: Physiological basis and strategies to improve abiotic stress tolerance in crops. Ann. Bot. 2013, 112, 1209-1221. [CrossRef]

19. Zhao, Z.X.; Zhang, W.; Stanley, B.A.; Assmann, S.M. Functional proteomics of Arabidopsis thaliana guard cells uncovers new stomatal signaling pathways. Plant Cell 2008, 20, 3210-3226. [CrossRef]

20. Zhang, T.; Zhu, M.M.; Zhu, N.; Strul, J.M.; Dufresne, C.P.; Schneider, J.D.; Harmon, A.C.; Chen, S.X. Identification of thioredoxin targets in guard cell enriched epidermal peels using cysTMT proteomics. J. Proteomics 2016, 133, 48-53. [CrossRef]

21. Geng, S.; Yu, B.; Zhu, N.; Dufresne, C.; Chen, S. Metabolomics and proteomics of Brassica napus guard cells in response to low $\mathrm{CO}_{2}$. Front. Mol. Biosci. 2017, 4, 51. [CrossRef] [PubMed]

22. Zhao, Z.X.; Stanley, B.A.; Zhang, W.; Assmann, S.M. ABA-Regulated G Protein Signaling in Arabidopsis Guard Cells: A Proteomic Perspective. J. Proteome Res. 2010, 9, 1637-1647. [CrossRef] [PubMed]

23. Rasouli, F.; Kiani-Pouya, A.; Li, L.; Zhang, H.; Chen, Z.; Hedrich, R.; Wilson, R.; Shabala, S. Sugar beet (Beta vulgaris) guard cells responses to salinity stress: A proteomic analysis. Int. J. Mol. Sci. 2020, 21, 7. [CrossRef] [PubMed]

24. Chen, Y.; Wang, X.M.; Zhou, L.; He, Y.; Wang, D.; Qi, Y.H.; Jiang, D.A. Rubisco activase is also a multiple responder to abiotic stresses in rice. PLoS ONE 2015, 10, e0140934. [CrossRef]

25. Lee, D.S.; Kim, B.K.; Kwon, S.J.; Jin, H.C.; Park, O.K. Arabidopsis GDSL lipase 2 plays a role in pathogen defense via negative regulation of auxin signaling. Biochem. Bioph. Res. Co. 2009, 379, 1038-1042. [CrossRef]

26. Schwacke, R.; Ponce-Soto, G.Y.; Krause, K.; Bolger, A.M.; Arsova, B.; Hallab, A.; Gruden, K.; Stitt, M.; Bolger, M.E.; Usadel, B. MapMan4: A refined protein classification and annotation framework applicable to multi-omics data analysis. Mol. Plant 2019, 12, 879-892. [CrossRef]

27. Cotelle, V.; Leonhardt, N. 14-3-3 proteins in guard cell signaling. Front. Plant Sci. 2015, 6, 1210. [CrossRef]

28. Kretzschmar, T.; Burla, B.; Lee, Y.; Martinoia, E.; Nagy, R. Functions of ABC transporters in plants. Essays Biochem. 2011, $50,145-160$.

29. Hubbard, K.E.; Webb, A.A. Circadian rhythms in stomata: Physiological and molecular aspects. In Rhythms in Plants, 2nd ed.; Mancuso, S., Shabala, S., Eds.; Springer International Publishing: Cham, Switzerland, 2015; pp. 231-255.

30. Willmer, C.M.; Grammatikopoulos, G.; LascÈve, G.; Vavasseur, A. Characterization of the vacuolar-type $\mathrm{H}^{+}$-ATPase from guard cell protoplasts of Commelina. J. Exp. Bot. 1995, 46, 383-389. [CrossRef] 
31. Taji, T.; Seki, M.; Satou, M.; Sakurai, T.; Kobayashi, M.; Ishiyama, K.; Narusaka, Y.; Narusaka, M.; Zhu, J.K.; Shinozaki, K. Comparative genomics in salt tolerance between Arabidopsis and Arabidopsis-related halophyte salt cress using Arabidopsis microarray. Plant Physiol. 2004, 135, 1697-1709. [CrossRef]

32. Laloum, T.; Martín, G.; Duque, P. Alternative splicing control of abiotic stress responses. Trends Plant Sci. 2018, 23, 140-150. [CrossRef] [PubMed]

33. Sun, J.; Jiang, H.; Xu, Y.; Li, H.; Wu, X.; Xie, Q.; Li, C. The CCCH-type zinc finger proteins AtSZF1 and AtSZF2 regulate salt stress responses in Arabidopsis. Plant Cell Physiol. 2007, 48, 1148-1158. [CrossRef] [PubMed]

34. Wang, Y.; Zhong, Z.; Zhang, Y.; Xu, L.; Feng, S.; Rayatpisheh, S.; Wohlschlegel, J.A.; Wang, Z.; Jacobsen, S.E.; Ausin, I. NAP1RELATED PROTEIN1 and 2 negatively regulate H2A.Z abundance in chromatin in Arabidopsis. Nat. Commun. 2020, $11,2887$. [CrossRef] [PubMed]

35. Wu, H.C.; Bulgakov, V.P.; Jinn, T.L. Pectin Methylesterases: Cell wall remodeling proteins are required for plant response to heat stress. Front. Plant Sci. 2018, 9, 1612. [CrossRef]

36. Huang, Y.C.; Wu, H.C.; Wang, Y.D.; Liu, C.H.; Lin, C.C.; Luo, D.L.; Jinn, T.L. PECTIN METHYLESTERASE34 Contributes to heat tolerance through its role in promoting stomatal movement. Plant Physiol. 2017, 174, 748-763. [CrossRef]

37. Ringli, C.; Keller, B.; Ryser, U. Glycine-rich proteins as structural components of plant cell walls. Cell Mol. Life Sci. 2001, 58, 1430-1441. [CrossRef]

38. Bose, J.; Munns, R.; Shabala, S.; Gilliham, M.; Pogson, B.; Tyerman, S.D. Chloroplast function and ion regulation in plants growing on saline soils: Lessons from halophytes. J. Exp. Bot. 2017, 68, 3129-3143. [CrossRef]

39. Naranjo, M.A.; Forment, J.; Roldan, M.; Serrano, R.; Vicente, O. Overexpression of Arabidopsis thaliana LTL1, a salt-induced gene encoding a GDSL-motif lipase, increases salt tolerance in yeast and transgenic plants. Plant Cell Environ. 2006, 29, 1890-1900. [CrossRef]

40. Le, J.; Liu, X.G.; Yang, K.Z.; Chen, X.L.; Zou, J.J.; Wang, H.Z.; Wang, M.; Vanneste, S.; Morita, M.; Tasaka, M.; et al. Auxin transport and activity regulate stomatal patterning and development. Nat. Commun. 2014, 5, 3090. [CrossRef]

41. Thiel, G.; Blatt, M.R.; Fricker, M.D.; White, I.R.; Millner, P. Modulation of $\mathrm{K}^{+}$channels in vicia stomatal guard-cells by peptide homologs to the auxin-binding protein-C terminus. Proc. Natl. Acad. Sci. USA 1993, 90, 11493-11497. [CrossRef]

42. Gehring, C.A.; McConchie, R.M.; Venis, M.A.; Parish, R.W. Auxin-binding-protein antibodies and peptides influence stomatal opening and alter cytoplasmic pH. Planta 1998, 205, 581-586. [CrossRef]

43. Azoulay-Shemer, T.; Palomares, A.; Bagheri, A.; Israelsson-Nordstrom, M.; Engineer, C.B.; Bargmann, B.O.; Stephan, A.B.; Schroeder, J.I. Guard cell photosynthesis is critical for stomatal turgor production, yet does not directly mediate $\mathrm{CO}_{2}{ }^{-}$and ABA-induced stomatal closing. Plant J. 2015, 83, 567-581. [CrossRef]

44. Iwai, S.; Ogata, S.; Yamada, N.; Onjo, M.; Sonoike, K.; Shimazaki, K.I. Guard cell photosynthesis is crucial in abscisic acid-induced stomatal closure. Plant Direct 2019, 3, e00137. [CrossRef]

45. Lüttge, U.; Beck, E.; Bartels, D. Plant dessication tolerance. In Ecological Studies Book 215; Springer: Berlin, Germany, 2011.

46. Nylander, M.; Svensson, J.; Tapio Palva, E.; Welin, B.V. Stress-induced accumulation and tissue-specific localization of dehydrins in Arabidopsis thaliana. Plant Mol. Biol. 2001, 45, 263-279. [CrossRef] [PubMed]

47. Hyun, T.K.; van der Graaff, E.; Albacete, A.; Eom, S.H.; Grosskinsky, D.K.; Bohm, H.; Janschek, U.; Rim, Y.; Ali, W.W.; Kim, S.Y.; et al. The Arabidopsis PLAT domain protein1 is critically involved in abiotic stress tolerance. PLoS ONE 2014, 9, e112946. [CrossRef] [PubMed]

48. Kaashyap, M.; Ford, R.; Kudapa, H.; Jain, M.; Edwards, D.; Varshney, R.; Mantri, N. Differential regulation of genes involved in root morphogenesis and cell wall modification is associated with salinity tolerance in chickpea. Sci. Rep. 2018, 8, 4855. [CrossRef]

49. Saucedo-Garcia, M.; Gavilanes-Ruiz, M.; Arce-Cervantes, O. Long-chain bases, phosphatidic acid, MAPKs, and reactive oxygen species as nodal signal transducers in stress responses in Arabidopsis. Front. Plant Sci. 2015, 6, 55.

50. Yao, X.; Xiong, W.; Ye, T.T.; Wu, Y. Overexpression of the aspartic protease ASPG1 gene confers drought avoidance in Arabidopsis. J. Exp. Bot. 2012, 63, 2579-2593. [CrossRef]

51. Granot, D.; Kelly, G. Evolution of guard-cell theories: The story of sugars. Trends Plant Sci. 2019, 24, 507-518. [CrossRef] [PubMed]

52. Outlaw, W.H.; Manchester, J. Guard cell starch concentration quantitatively related to stomatal aperture. Plant Physiol. 1979, 64, 79-82. [CrossRef]

53. Kelly, G.; Moshelion, M.; David-Schwartz, R.; Halperin, O.; Wallach, R.; Attia, Z.; Belausov, E.; Granot, D. Hexokinase mediates stomatal closure. Plant J. 2013, 75, 977-988. [CrossRef] [PubMed]

54. Kottapalli, J.; David-Schwartz, R.; Khamaisi, B.; Brandsma, D.; Lugassi, N.; Egbaria, A.; Kelly, G.; Granot, D. Sucrose-induced stomatal closure is conserved across evolution. PLoS ONE 2018, 13, e0205359. [CrossRef] [PubMed]

55. Rasouli, F.; Kiani-Pouya, A.; Tahir, A.; Shabala, L.; Chen, Z.; Shabala, S. A comparative analysis of stomatal traits and photosynthetic responses in closely related halophytic and glycophytic species under saline conditions. Environ. Exp. Bot. 2021, 181, 104300. [CrossRef]

56. Jaarsma, R.; de Vries, R.S.; de Boer, A.H. Effect of salt stress on growth, $\mathrm{Na}^{+}$accumulation and proline metabolism in potato (Solanum tuberosum) cultivars. PLoS ONE 2013, 8, e60183. [CrossRef]

57. Cuin, T.A.; Shabala, S. Amino acids regulate salinity-induced potassium efflux in barley root epidermis. Planta 2007, 225, 753-761. [CrossRef] 
58. Sharma, U.D.; Rai, V.K. Modulation of osmotic closure of stomata, stomatal resistance and $\mathrm{K}^{+}$fluxes by exogenous amino acids in Vicia faba L. Leaves. Biochem. Physiol. Pfl. 1989, 185, 369-376. [CrossRef]

59. Kong, D.; Hu, H.C.; Okuma, E.; Lee, Y.; Lee, H.S.; Munemasa, S.; Cho, D.; Ju, C.; Pedoeim, L.; Rodriguez, B.; et al. L-Met activates Arabidopsis GLR Ca ${ }^{2+}$ channels upstream of ROS production and regulates stomatal movement. Cell Rep. 2016, 17, $2553-2561$. [CrossRef]

60. Simões, I.; Faro, C. Structure and function of plant aspartic proteinases. Eur. J. Biochem. 2004, 271, 2067-2075. [CrossRef]

61. Soares, A.; Ribeiro Carlton, S.M.; Simoes, I. Atypical and nucellin-like aspartic proteases: Emerging players in plant developmental processes and stress responses. J. Exp. Bot. 2019, 70, 2059-2076. [CrossRef]

62. Guo, R.; Zhao, J.; Wang, X.; Guo, C.; Li, Z.; Wang, Y.; Wang, X. Constitutive expression of a grape aspartic protease gene in transgenic Arabidopsis confers osmotic stress tolerance. Plant Cell Tissue Organ Cult. 2015, 121, 275-287. [CrossRef]

63. Williams, M.; Woodward, F.I.; Baldocchi, D.D.; Ellsworth, D.S. Leaf to landscape. In Photosynthetic Adaptation; Smith, W.K., Vogelmann, T.C., Critchley, C., Eds.; Springer: New York, NY, USA, 2004; pp. 133-168.

64. Rawlings, N.D.; Barrett, A.J. Families of aspartic peptidases, and those of unknown catalytic mechanism. Method Enzymol. 1995, 28, 105-120.

65. Yamauchi, S.; Mano, S.; Oikawa, K.; Hikino, K.; Teshima, K.M.; Kimori, Y.; Nishimura, M.; Shimazaki, K.I.; Takemiya, A. Autophagy controls reactive oxygen species homeostasis in guard cells that is essential for stomatal opening. Proc. Natl. Acad. Sci. USA 2019, 116, 19187-19192. [CrossRef] [PubMed]

66. Zou, C.; Chen, A.; Xiao, L.; Muller, H.M.; Ache, P.; Haberer, G.; Zhang, M.; Jia, W.; Deng, P.; Huang, R.; et al. A high-quality genome assembly of quinoa provides insights into the molecular basis of salt bladder-based salinity tolerance and the exceptional nutritional value. Cell Res. 2017, 27, 1327-1340. [CrossRef] [PubMed]

67. Jarvis, D.E.; Ho, Y.S.; Lightfoot, D.J.; Schmockel, S.M.; Li, B.; Borm, T.J.; Ohyanagi, H.; Mineta, K.; Michell, C.T.; Saber, N.; et al. The genome of Chenopodium quinoa. Nature 2017, 542, 307-312. [CrossRef] [PubMed]

68. Rasouli, F.; Kiani-Pouya, A.; Zhang, H.; Shabala, S. Developing and validating protocols for mechanical isolation of guard-cell enriched epidermal peels for omics studies. Funct. Plant Biol. 2020, 47, 803-814. [CrossRef] [PubMed]

69. Hughes, C.S.; Moggridge, S.; Muller, T.; Sorensen, P.H.; Morin, G.B.; Krijgsveld, J. Single-pot, solid-phase-enhanced sample preparation for proteomics experiments. Nat. Protoc. 2019, 14, 68-85. [CrossRef] 